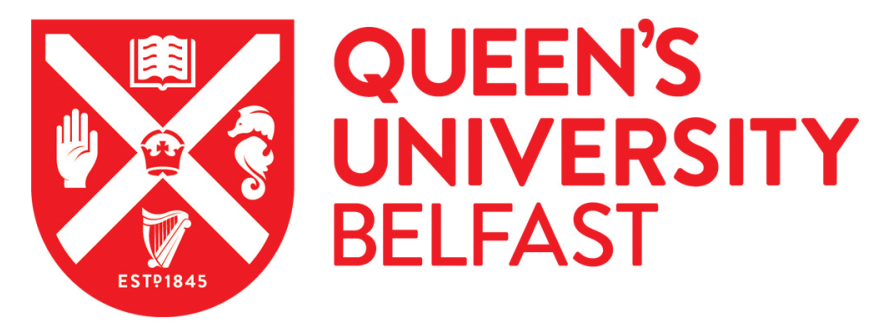

\title{
Understanding farmers' and veterinarians' behavior in relation to antimicrobial use and resistance in dairy cattle: A systematic review
}

Farrell, S., McKernan, C., Benson, T., Elliott, C., \& Dean, M. (2021). Understanding farmers' and veterinarians' behavior in relation to antimicrobial use and resistance in dairy cattle: A systematic review. Journal of Dairy Science. https://doi.org/10.3168/jds.2020-19614

Published in:

Journal of Dairy Science

Document Version:

Peer reviewed version

Queen's University Belfast - Research Portal:

Link to publication record in Queen's University Belfast Research Portal

Publisher rights

Copyright 2021 Elsevier.

This manuscript is distributed under a Creative Commons Attribution-NonCommercial-NoDerivs License

(https://creativecommons.org/licenses/by-nc-nd/4.0/), which permits distribution and reproduction for non-commercial purposes, provided the author and source are cited.

\section{General rights}

Copyright for the publications made accessible via the Queen's University Belfast Research Portal is retained by the author(s) and / or other copyright owners and it is a condition of accessing these publications that users recognise and abide by the legal requirements associated with these rights.

Take down policy

The Research Portal is Queen's institutional repository that provides access to Queen's research output. Every effort has been made to ensure that content in the Research Portal does not infringe any person's rights, or applicable UK laws. If you discover content in the Research Portal that you believe breaches copyright or violates any law, please contact openaccess@qub.ac.uk. 
1 Understanding farmer and veterinarian's behavior in relation to antimicrobial use and

2 resistance in dairy cattle: A systematic review

3 S. Farrell*, C. McKernan*, T. Benson*, C. Elliott* and ${ }^{1}$ M. Dean*

4 *Institute for Global Food Security, School of Biological Sciences, Queen's University

5 Belfast, 19 Chlorine Gardens, Belfast BT9 5DL

6

7 Sarah Farrell. Institute for Global Food Security, School of Biological Sciences, Queen's

8 University Belfast, 19 Chlorine Gardens, Belfast BT9 5DL. Sfarrell11@qub.ac.uk

9 Claire McKernan. Institute for Global Food Security, School of Biological Sciences, Queen's

10 University Belfast, 19 Chlorine Gardens, Belfast BT9 5DL. C.mckernan@qub.ac.uk

11 Tony Benson. Institute for Global Food Security, School of Biological Sciences, Queen's

12 University Belfast, 19 Chlorine Gardens, Belfast BT9 5DL. T.benson@qub.ac.uk

13 Chris Elliott. Institute for Global Food Security, School of Biological Sciences, Queen's

14 University Belfast, 19 Chlorine Gardens, Belfast BT9 5DL. Chris.elliott@qub.ac.uk

${ }^{1}$ Moira Dean. Institute for Global Food Security, School of Biological Sciences, Queen's 


\section{ABSTRACT}

To tackle antimicrobial resistance, it is vital that dairy farmers and veterinarians antimicrobial use behaviors and attitudes towards resistance are understood to identify how beliefs and motives influence practices. Current literature details qualitative and quantitative research exploring dairy farmer and veterinarian's knowledge, attitudes and perceptions on antimicrobial resistance and antimicrobial practices with varied and conflicting reported findings. Our objective was therefore to conduct a systematic review to assess the evidence and knowledge gaps in published literature. Articles were identified via database searches of Embase, Medline, PubMed, Scopus and Web of Science and were limited to published articles available in English with no publication year restrictions. Article screening was conducted at 3 levels: title, abstract and full text. Of the 349 articles identified, 35 were retained for systematic review. Transparency of reporting was assessed for each study using the Consolidated Criteria for Reporting Qualitative Research (COREQ) framework. Quality was assessed using the Critical Appraisal Skills Programme (CASP) qualitative checklist. Findings relating to dairy farmers and veterinarian's knowledge, attitudes and perceptions on antimicrobial resistance and practices were thematically analysed. Comprehensiveness of reporting was variable: studies reported between 5 and 26 of the 32 COREQ checklist items. Five key themes emerged from the data: (1) Knowledge and awareness of antimicrobial resistance, (2) Factors influencing farmer and veterinarian decision making, (3) Perceived barriers and facilitators to reduced antimicrobial use, (4) Perceived responsibility to antimicrobial resistance and (5) The role of the farmer and veterinarian relationship in reducing antimicrobial use. Awareness of prudent antimicrobial use was not uniform between reviewed studies. Many factors influence farmer and veterinarian's decisions to use antimicrobials including animal welfare and available resources. The farmer-veterinarian relationship is considered a potential barrier or facilitator of reduced antimicrobial use, depending on the 
52 perceived relationship dynamic. Encouraging collaboration between farmers and veterinarians could lead to a shared responsibility to reducing antimicrobial use. This review provided a coherent picture of what is currently known and identified gaps in the current knowledge to be used to inform future behavioural intervention research. Increased knowledge, skill development, increased resources, increased engagement, and further research to address the gaps identified are the main recommendations to effectively overcome barriers and elicit appropriate behavior change to achieve reduced antimicrobial use in dairy cattle.

KEYWORDS: Antimicrobial Resistance; Antimicrobial Use; Dairy Farmers; Veterinary Medicine; Systematic Review

\section{INTRODUCTION}

Antimicrobial resistance (AMR) occurs naturally when microorganisms are exposed to antimicrobial drugs. Under selective pressure, susceptible bacteria are killed or inhibited while bacteria which are naturally resistant or have acquired AMR have a greater chance of survival and risk of disease spread (Prestinaci, Pezzotti and Pantosti, 2015). AMR is a major global health challenge (WHO, 2014) as many lifesaving interventions such as chemotherapy and organ transplant rely on effective antimicrobials (Telliant et al., 2015). Therefore, AMR places humans and animals at substantial increased risk of prolonged illness or death from infection (Lambert et al., 2011). Experts have warned that if AMR continues to rise, so too will the associated social and economic costs (O’Neill, 2014).

Limiting antimicrobial use (AMU) is acknowledged as a vital step in limiting AMR development (WHO, 2017). Inappropriate AMU includes over or under prescribing, inappropriate dosing, incorrect treatment duration or drug choice and unnecessary use of expensive drugs when established, cheaper and clinically adequate drugs are available (WHO, 2000). "Prudent use" of antimicrobials involves avoiding inappropriate AMU to 
preserve their efficacy for as long as possible (Centers for Disease Control and Prevention, 2007). There is scientific recognition that antibiotic use in agriculture can lead to consequential resistance in the environment and implications on public health (Manyi-Loh et al., 2018). It is widely acknowledged that research and policy efforts are needed to reduce agricultural AMU (FAO, 2016). A recent systematic review concluded that interventions which aim to restrict AMU in livestock are associated with reduced AMR in such animals (Tang et al., 2017).

Understanding stakeholder attitudes, decision-making and the translation of behavioral intentions into sustained behavior change is an increasingly important discipline for policy design (Jones et al., 2015). Studies exploring the reasons for current AMU in agriculture are needed to design effective interventions to promote prudent agricultural AMU (Fischer et al., 2019). Monitoring of AMU in livestock alone reveals little about what is driving AMU and so it is important to assess the behaviors of key stakeholders responsible for antimicrobial prescription and administration (Friedman et al., 2007).

It is important to understand dairy farmer and veterinarians AMU behaviors and attitudes towards AMR to identify how their beliefs and motives influence their AMU (Busani et al., 2004). It has previously been reported that understanding farmers' motivations to implement recommended practices is necessary to reduce AMU (Poizat et al., 2017) as well as measuring knowledge and behaviors which protect both animals and humans from AMR and disease transfer (Friedman et al., 2007). In addition, there is a need to characterize on-farm AMU and identify the key drivers of responsible AMU, it is anticipated that such findings can inform interventions to reduce AMU on dairy farms (Higham et al., 2018).

Both qualitative and quantitative research methods have been used previously to explore topics such as dairy farmer and veterinarian's knowledge, attitudes and perceptions of AMR 
and their individual AMU practices. Such research methodologies focus on one or two of these areas with a range of findings presented and so research exploring all of the above aspects are scarce. Previous studies have not followed a common methodology and the aims of such papers have been broad ranging. In order to obtain a more in-depth knowledge of what is currently known, this review aimed to collate and synthesise all available published data relating to the knowledge, attitudes and perceptions that dairy farmers and veterinarians have of AMR and their individual AMU practices. This will provide a coherent picture of what is currently known, identifying commonalities and contradictions in findings between studies and identify gaps in the current knowledge to inform future behavioral analysis research and AMU intervention design.

\section{MATERIALS AND METHODS}

\section{Review approach}

This review was reported in accordance with the Enhancing transparency in reporting the synthesis of qualitative research (ENTREQ) framework, a reporting guideline for synthesis of qualitative research (Tong et al., 2012). A copy of the framework is available as supplementary information (https://doi.org/10.6084/m9.figshare.13721083.v1). In order to address the research question, the articles of interest were those which explored dairy farmer and dairy veterinarian's knowledge, awareness, attitudes and perceptions of antimicrobial use and antimicrobial resistance.

\section{Search strategy}

In November and December 2019 a pre-planned, comprehensive, and systematic search of electronic databases was undertaken to seek all available studies related to the research question. To obtain relevant articles, literature searches on Embase, Medline, PubMed, Scopus and Web of Science were conducted. Articles included in the review were 


\section{DAIRY ANTIMICROBIAL USE: A SYSTEMATIC REVIEW}

predominantly obtained via databases and where applicable, additional articles were retrieved from the reference lists of published articles. The search terms used in the databases include "Dairy Farmer", "Dairy Veterinarian”, “Antimicrobial use", Antibiotic use” and

"Antimicrobial resistance". Each database was searched multiple times using combinations of the previously mentioned terms in order to yield as many relevant articles as possible. Full details of the search terms used, and results yielded from each database search is available as supplementary information (https://doi.org/10.6084/m9.figshare.13721083.v1). The search criteria for this review was limited to published peer-reviewed articles available in English and no publication date limits were placed on the database searches. Only peer reviewed journal articles aiming to explore the knowledge, awareness, attitudes or perceptions of dairy farmers or veterinarians were included in the review. Studies utilising surveys, questionnaires, interviews, and focus groups were included. Screening and data extraction

Articles were retained for review if the study population was comprised of or included dairy farmers and dairy veterinarians. Articles were excluded if the research was focused on the quantity of antimicrobial use on farms, did not focus on the dairy farmer or veterinarian's perspective in regard to AMU/AMR and if no independent research method was outlined. Following the removal of duplicates, articles obtained from all sources were screened for eligibility based on title and abstract $(n=211)$. Articles were deemed eligible if they met the outlined inclusion criteria. Following a full text review of articles $(n=76)$, those deemed eligible $(\mathrm{n}=35)$ were retained for systematic review. Articles were only included if the data collection methods were adequately outlined i.e. gave details of the study population, sampling method and data analysis. Figure 1 illustrates the process of searching, screening, and identifying studies for inclusion in this systematic synthesis. 
147 For each of the articles identified as eligible for this review, all text under the headings "results" were extracted from the articles and exported into qualitative data analysis software NVivo 12 (QSR International Pty Ltd, Doncaster, Victoria, Australia) for data synthesis.

Transparency of reporting was assessed for each study using the Consolidated Criteria for Reporting Qualitative Research (COREQ) framework (Tong, Sainsbury \& Craig, 2007). The quality of the included studies was assessed using the Critical Appraisal Skills Programme Qualitative Research Checklist (Critical Appraisal Skills Programme, 2017). Appraisal was conducted by the first author (SF) then discussed and agreed upon with other authors. No study with data relevant to the aim of the review was excluded from the synthesis.

\section{Data analysis}

157 Extracted findings were thematically analysed inductively in line with the Braun and Clarke, (2006) protocol allowing for themes to be constructed from the data. Extracted findings from each article were coded line by line to search for information of interest to the research question. All data relating to farmers and veterinarian's knowledge, awareness, attitudes and perceptions of AMR and reduced AMU were coded. Codes were then grouped, along with their related data into potential themes identifying overlap and commonalities and where necessary themes were refined (I.e. collapsed or divided). At this stage extracted findings were re-read to ensure no data had been missed in earlier coding stages. Coding was performed by one author (SF) and then subsequently reviewed and approved by two additional authors (MD and TB).

Thirty-five studies which collected data from 5537 participants were deemed relevant for this review. An overview of the study characteristics is presented in figure 2 . The study population of 20 articles were exclusively farmers (17 dairy farmers only), eight were 
171

172

173

174

175

176

177

178

179

exclusively veterinarians ( 3 dairy veterinarians only) and 7 had a multi stakeholder study

population which included dairy farmers and dairy veterinarians. Just over half of the studies

utilised surveys as the data collection method (54.3\%). Interviews (25.7\%), mixed methods

$(14.3 \%)$ and focus groups $(5.7 \%)$ were also used as the data collection methods. Studies were conducted in mainland Europe (14), USA (8), United Kingdom (5), Asia (3), South America

(2), North America (1), Oceania (1) and Africa (1). All included studies were published

between 2002 and 2019. Thematic analysis identified five key themes within the data, themes

and sub-themes are presented in figure 3. Table 1 summarises the key findings and

recommendations made based on systematic review.

Table 1: Summary of the main review findings and recommendations made in relation to achieving reduced antimicrobial use on dairy farms based on systematic review

\begin{tabular}{|c|c|c|c|}
\hline $\begin{array}{l}\text { Recommendations made } \\
\text { based on systematic review }\end{array}$ & $\begin{array}{l}\text { Relevant } \\
\text { stakeholder }\end{array}$ & $\begin{array}{l}\text { Findings to support } \\
\text { recommendation }\end{array}$ & References \\
\hline $\begin{array}{l}\text { Increased knowledge } \\
\text { On AMR }{ }^{1} \text { in dairy cattle, its } \\
\text { impact on human AMR and } \\
\text { the role farmers and } \\
\text { veterinarians can play in } \\
\text { the development and spread } \\
\text { of AMR }\end{array}$ & $\begin{array}{l}\text { Dairy Farmers } \\
\text { and } \\
\text { Dairy } \\
\text { Veterinarians }\end{array}$ & $\begin{array}{l}\text { Variations in } \\
\text { knowledge and } \\
\text { awareness of AMR in } \\
\text { dairy cattle. } \\
\text { Lack of knowledge } \\
\text { regarding the link } \\
\text { between animal and } \\
\text { human AMR. } \\
\text { Imbalance in farmer } \\
\text { and veterinarian's } \\
\text { recognition of their } \\
\text { role in AMR }\end{array}$ & $\begin{array}{l}\text { Higham et al., 2018; } \\
\text { Raymond et al., 2006; } \\
\text { Friedman et al., 2007; } \\
\text { Redding et al., 2014; Sadiq } \\
\text { et al., 2018; Chauhan et al., } \\
\text { 2018; Jones et al., 2015; } \\
\text { Poizat et al., 2017; Kumar } \\
\text { \& Gupta 2018; Ekakoro et } \\
\text { al., 2018; Speksnijder et al., } \\
\text { 2015; Léger et al., 2015; } \\
\text { Golding et al., 2019; } \\
\text { Swinkles et al., 2015; } \\
\text { McDougall et al., 2017; } \\
\text { Magalhaes Sant'Ana et al., } \\
\text { 2017; Cattaneo et al., } 2009\end{array}$ \\
\hline $\begin{array}{l}\text { How economic risks can be } \\
\text { minimised while reducing } \\
\text { on farm } \mathrm{AMU}^{2}\end{array}$ & $\begin{array}{l}\text { Dairy Farmers } \\
\text { Dairy } \\
\text { Veterinarians }\end{array}$ & $\begin{array}{l}\text { Concerns due to } \\
\text { economic risks } \\
\text { associated with } \\
\text { reducing AMU on } \\
\text { farm such as animal } \\
\text { mortality and farm } \\
\text { productivity }\end{array}$ & $\begin{array}{l}\text { Raymond et al., 2006; } \\
\text { Friedman et al., 2007; } \\
\text { Speksnijder et al., 2015; } \\
\text { Magalhaes Sant'Ana et } \\
\text { al., 2017; Fischer et al., } \\
\text { 2019; Golding et al., } \\
2019\end{array}$ \\
\hline
\end{tabular}




\begin{tabular}{|c|c|c|c|}
\hline $\begin{array}{l}\text { Skill development } \\
\text { Improved ability and } \\
\text { confidence to implement } \\
\text { prudent AMU practices } \\
\text { while maintaining animal } \\
\text { welfare standards }\end{array}$ & $\begin{array}{l}\text { Dairy Farmers } \\
\text { Dairy } \\
\text { Veterinarians }\end{array}$ & $\begin{array}{l}\text { Variations in } \\
\text { awareness of prudent } \\
\text { practices. Variations } \\
\text { in perceived ability to } \\
\text { implement reduced } \\
\text { AMU. AMU deemed } \\
\text { necessary for animal } \\
\text { welfare }\end{array}$ & $\begin{array}{l}\text { Ekakoro et al., 2018; Jones } \\
\text { et al., 2015; Poizat et al., } \\
\text { 2017; Kumar \& Gupta } \\
\text { 2018; Redding et al., 2014; } \\
\text { Higham et al., 2018; } \\
\text { Vasquez et al., 2019; } \\
\text { Fischer et al., 2019; } \\
\text { Speksnijder et al., 2015; } \\
\text { Golding et al., 2019; Orpin, } \\
\text { 2007; Scherpenzeel et al., } \\
\text { 2016 \& 2018. }\end{array}$ \\
\hline $\begin{array}{l}\text { Improved ability to prevent } \\
\text { and manage mastitis and } \\
\text { other disease while } \\
\text { reducing AMU via } \\
\text { improved biosecurity and } \\
\text { herd management measures }\end{array}$ & $\begin{array}{l}\text { Dairy Farmers } \\
\text { Dairy } \\
\text { Veterinarians }\end{array}$ & $\begin{array}{l}\text { Mastitis is the most } \\
\text { commonly reported } \\
\text { reason for AMU in } \\
\text { dairy cattle. } \\
\text { Biosecurity and herd } \\
\text { management } \\
\text { recognised by many } \\
\text { farmers and } \\
\text { veterinarians as } \\
\text { important steps to } \\
\text { reduce AMU on farm }\end{array}$ & $\begin{array}{l}\text { Jones et al., 2015; } \\
\text { Raymond et al., 2006; } \\
\text { Carmo et al., 2018, } \\
\text { Ekabro et al., 2018; } \\
\text { Fischer et al., 2019; } \\
\text { Higham et al., 2018; } \\
\text { Kayitsinga et al., 2017; } \\
\text { Vaarst et al., 2003; } \\
\text { Cattaneo et al., 2009; } \\
\text { Speksnijder et al. 2015; } \\
\text { Holstege et al., 2018; } \\
\text { Kumar and Gupta, 2018 }\end{array}$ \\
\hline $\begin{array}{l}\text { Increased resources } \\
\text { Time and labour } \\
\text { requirements of an } \\
\text { intervention should be } \\
\text { considered to ensure } \\
\text { successful implementation }\end{array}$ & $\begin{array}{l}\text { Dairy Farmers } \\
\text { Dairy } \\
\text { Veterinarians }\end{array}$ & $\begin{array}{l}\text { Time constraints and } \\
\text { labour burden } \\
\text { reported as barriers to } \\
\text { achieving reduced } \\
\text { AMU }\end{array}$ & $\begin{array}{l}\text { Friedman et al., 2007; } \\
\text { Golding et al., 2019; Poizat } \\
\text { et al., 2017; Scherpenzeel et } \\
\text { al. 2016; Speksnijder et al. } \\
2015\end{array}$ \\
\hline $\begin{array}{l}\text { Increased engagement } \\
\text { Encouraging veterinarians } \\
\text { to take on a proactive role } \\
\text { in promoting alternatives to } \\
\text { antimicrobials }\end{array}$ & $\begin{array}{l}\text { Dairy } \\
\text { Veterinarians }\end{array}$ & $\begin{array}{l}\text { Veterinarians are } \\
\text { seen by many } \\
\text { farmers as having the } \\
\text { ability to facilitate } \\
\text { reduced AMU. }\end{array}$ & $\begin{array}{l}\text { Scherpenzeel et al., } \\
\text { 2016; Golding et al., } \\
2019\end{array}$ \\
\hline $\begin{array}{l}\text { Encouraging farmers to } \\
\text { utilise veterinary services } \\
\text { and advice to reduce AMU }\end{array}$ & Dairy Farmers & $\begin{array}{l}\text { Farmers do not } \\
\text { always seek } \\
\text { veterinary advice due } \\
\text { to the fees associated } \\
\text { with their services. } \\
\end{array}$ & Friedman et al., 2007 \\
\hline $\begin{array}{l}\text { Further research } \\
\text { To obtain a clearer picture } \\
\text { of the prophylactic use of } \\
\text { antimicrobials in dairy } \\
\text { cattle }\end{array}$ & $\begin{array}{l}\text { Dairy Farmers } \\
\& \\
\text { Veterinarians }\end{array}$ & $\begin{array}{l}\text { Limited published } \\
\text { data on the } \\
\text { prophylactic AMU } \\
\text { on dairy farms. }\end{array}$ & $\begin{array}{l}\text { Busani et al., 2004; } \\
\text { Redding et al., 2014; } \\
\text { Speksnijder et al., } \\
2015\end{array}$ \\
\hline $\begin{array}{l}\text { To explore how the } \\
\text { opinions of others may } \\
\text { influence farmer and } \\
\text { veterinarian decision } \\
\text { making regarding AMU }\end{array}$ & $\begin{array}{l}\text { Dairy Farmers } \\
\text { Dairy } \\
\text { Veterinarians }\end{array}$ & $\begin{array}{l}\text { Many farmers and } \\
\text { veterinarians are } \\
\text { motivated by social } \\
\text { norms within the } \\
\text { industry. }\end{array}$ & $\begin{array}{l}\text { Jones et al., } 2015 \\
\text { Scherpenzeel et al. } \\
2016 \\
\text { Scherpenzeel et al. } \\
2018\end{array}$ \\
\hline
\end{tabular}




\begin{tabular}{|c|c|c|c|}
\hline $\begin{array}{l}\text { To determine the influence } \\
\text { farmers have on } \\
\text { veterinarian's decision to } \\
\text { prescribe antimicrobials } \\
\text { and how this can be } \\
\text { minimised }\end{array}$ & $\begin{array}{l}\text { Dairy } \\
\text { Veterinarians }\end{array}$ & $\begin{array}{l}\text { Some veterinarians } \\
\text { perceive pressure } \\
\text { from farmers to } \\
\text { prescribe } \\
\text { antimicrobials and } \\
\text { the perceived skills } \\
\text { and knowledge of } \\
\text { farmers can influence } \\
\text { prescribing decisions. }\end{array}$ & $\begin{array}{l}\text { Speksnijder et al. } \\
\text { 2015; Higgins et al., } \\
\text { 2017; Redding et al., } \\
\text { 2013; Golding et al., } \\
2019\end{array}$ \\
\hline $\begin{array}{l}\text { To enable farmers and } \\
\text { veterinarians to work } \\
\text { together confidently and } \\
\text { effectively to reduce AMU }\end{array}$ & $\begin{array}{l}\text { Dairy Farmers } \\
\text { Dairy } \\
\text { Veterinarians }\end{array}$ & $\begin{array}{l}\text { Many farmers and } \\
\text { veterinarians are } \\
\text { open to a more } \\
\text { collaborative } \\
\text { working relationship } \\
\text { in order to achieve } \\
\text { reduced AMU }\end{array}$ & $\begin{array}{l}\text { Golding et al., 2019; } \\
\text { Magalhaes Sant'Ana, } \\
2017\end{array}$ \\
\hline $\begin{array}{l}\text { To ensure harmonised } \\
\text { policy and regulation } \\
\text { relating to AMU in dairy } \\
\text { cattle globally }\end{array}$ & $\begin{array}{l}\text { Dairy Farmers } \\
\text { Dairy } \\
\text { Veterinarians }\end{array}$ & $\begin{array}{l}\text { Many farmers and } \\
\text { veterinarians would } \\
\text { be accepting of } \\
\text { harmonised policies } \\
\text { and regulation to } \\
\text { reduce AMU }\end{array}$ & $\begin{array}{l}\text { Chauhan et al., 2018; } \\
\text { Magalhaes Sant'Ana, } \\
\text { 2017; Carmo et al., } \\
\text { 2018; Speksnijder et } \\
\text { al. } 2015\end{array}$ \\
\hline $\begin{array}{l}\text { To utilise behaviour change } \\
\text { theory to determine } \\
\text { evidence-based strategies to } \\
\text { reduce AMU in dairy } \\
\text { farming }\end{array}$ & $\begin{array}{l}\text { Dairy Farmers } \\
\text { Dairy } \\
\text { Veterinarians }\end{array}$ & $\begin{array}{l}\text { Behaviour change is } \\
\text { considered difficult } \\
\text { within dairy farming } \\
\text { due to habitual } \\
\text { practices associated } \\
\text { with farming }\end{array}$ & Speksnijder et al. 2015 \\
\hline
\end{tabular}

183 Comprehensiveness of reporting varied between studies: studies reported between 5 and 26 of the 32 COREQ checklist items. COREQ checklist items are summarised in table 2 (Full COREQ assessment of each study is available as supplementary information: https://doi.org/10.6084/m9.figshare.13721083.v1).

Table 2: Overview of comprehensiveness of reporting for review studies based on Consolidated Criteria for Reporting

Qualitative Research (COREQ) framework

\begin{tabular}{|l|l|l|c|}
\hline COREQ Item & $\begin{array}{l}\text { Total } \\
\text { studies }\end{array}$ & COREQ Item & $\begin{array}{l}\text { Total } \\
\text { studies }\end{array}$ \\
\hline $\begin{array}{l}\text { Domain 1: Research team } \\
\text { and reflexivity } \\
\text { Personal Characteristics }\end{array}$ & $\underline{\text { Data collection }}$ & \\
\cline { 3 - 4 } 1. Interviewer/facilitator & $18 / 35$ & 17. Interview guide & $33 / 35$ \\
\hline 2. Credentials & $2 / 35$ & 19. Audio/visual recording & $1 / 35$ \\
\hline 3. Occupation & $9 / 35$ & 20. Field notes & $12 / 35$ \\
\hline 4. Gender & $5 / 35$ & 21. Duration & $4 / 35$ \\
\hline 5. Experience and training & $3 / 35$ & 22. Data saturation & $16 / 35$ \\
\hline
\end{tabular}




\begin{tabular}{|c|c|c|c|}
\hline \multicolumn{2}{|l|}{ Relationship with participants } & 23. Transcripts returned & $0 / 35$ \\
\hline 6. Relationship established & $1 / 35$ & \multirow{2}{*}{\multicolumn{2}{|c|}{$\begin{array}{l}\text { Domain 3: analysis and findings } \\
\text { Data analysis }\end{array}$}} \\
\hline $\begin{array}{l}\text { 7. Participant knowledge of the } \\
\text { interviewer }\end{array}$ & $3 / 35$ & & \\
\hline 8. Interviewer characteristics & $2 / 35$ & 24. Number of data coders & $8 / 35$ \\
\hline \multirow{2}{*}{\multicolumn{2}{|c|}{$\begin{array}{l}\text { Domain 2: study design } \\
\text { Theoretical framework }\end{array}$}} & 25. Description of the coding tree & $9 / 35$ \\
\hline & & 26. Derivation of themes & $16 / 35$ \\
\hline $\begin{array}{l}\text { 9. Methodological orientation and } \\
\text { Theory }\end{array}$ & $10 / 35$ & 27. Software & $19 / 35$ \\
\hline \multicolumn{2}{|l|}{ Participant selection } & 28. Participant checking & $0 / 35$ \\
\hline 10. Sampling & $35 / 35$ & \multicolumn{2}{|l|}{ Reporting } \\
\hline 11. Method of approach & $22 / 35$ & 29. Quotations presented & $11 / 35$ \\
\hline 12. Sample size & $34 / 35$ & 30. Data and findings consistent & $33 / 35$ \\
\hline 13. Non-participation & $4 / 35$ & 31. Clarity of major themes & $13 / 35$ \\
\hline \multicolumn{2}{|l|}{ Setting } & 32. Clarity of minor themes & $8 / 35$ \\
\hline 14. Setting of data collection & $30 / 35$ & Average no. COREQ items per study & 11 \\
\hline 15. Presence of non-participants & $1 / 35$ & Minimum no. COREQ items per study & 5 \\
\hline 16. Description of sample & $35 / 35$ & Maximum no. COREQ items per study & 26 \\
\hline
\end{tabular}

Theme 1: Farmer and veterinarians' knowledge and awareness of antimicrobial resistance

Previous reports suggest that a significant proportion of the farming community lack knowledge of prudent AMU and AMR (WHO, 2015). Within this review about a quarter of studies explored the knowledge and awareness farmers have of antimicrobials and AMR and the reported findings varied considerably. Studies of UK and Washington dairy farmers reported high levels of awareness (Higham et al., 2018; Raymond et al., 2006), while lower levels of knowledge and awareness were reported for South Carolina, Malaysian, Indian and Peruvian dairy farmers (Friedman et al., 2007; Redding et al., 2014; Sadiq et al., 2018; Chauhan et al., 2018). Knowledge and awareness of AMR were found to be higher within higher income countries therefore knowledge and awareness campaigns aiming to address AMR in dairy cattle should be disseminated globally and be consistent, with all farmers having access to this information. use of antimicrobials in animals to tackle AMR (Ozturk et al., 2019). Five studies within this 
review explored farmer awareness of appropriate AMU with variations in reported findings. Tennessee dairy farmers generally perceived their AMU to be prudent (Ekakoro et al., 2018) while those studied in the UK, India and France admitted to lacking knowledge and information about prudent AMU (Jones et al., 2015; Poizat et al., 2017; Kumar \& Gupta, 2018). Larger dairy farmers in India were more aware of the importance of animal husbandry practices in improving AMU compared with small farmers (Kumar and Gupta, 2018). Many Peruvian and Kenyan farmers lacked understanding of antimicrobial withdrawal times (Redding et al., 2014; Higham et al., 2016). This suggests that prudent AMU guidance should be disseminated globally to enable farmers to engage in practices which reduce the need for antimicrobials. Due to the variation of farm sizes globally, the ability to reach farmers may differ and it is important to ensure that farmers receive practical guidance relevant to the scale of their operations.

Previous literature shows that some livestock farmers do not have sufficient awareness of the severity of the problems resulting from AMR (Landfried et al., 2018, Moreno, 2014).This was explored by ten studies within this review with awareness of both farmers and veterinarians regarding the risks associated with AMR varying. Many South Carolina, Washington and UK dairy farmers were aware that increased AMU contributed to the development of AMR (Raymond et al., 2006; Friedman et al., 2007; Jones et al., 2015; Golding et al., 2019). Many Malaysian, Kenyan and Peruvian dairy farmers were aware that resistant bacteria could be difficult to treat and posed a threat to their animals (Redding et al., 2014; Higham et al., 2016; Sadiq et al., 2018). Large dairy farmers in India were more aware that the overuse of antibiotics increases the reservoir of antibiotic resistance in the food chain compared with small farmers (Kumar and Gupta, 2018). Most veterinarians understood the risks posed by AMU and agreed that it is important that AMU in livestock is restricted. UK veterinarians demonstrated good awareness and understanding of the risks posed in terms of 
animal welfare threats, farm income and productivity (Golding et al., 2019). Meanwhile most Canadian veterinarians agreed that AMU within the dairy industry, contributes to decreased antimicrobial efficacy in dairy cattle (Léger et al., 2015). In the Netherlands, almost all veterinarians (92\%) agreed (or partly agreed) that it is important that veterinary AMU is restricted to reduce AMR (Scherpenzeel et al., 2018). These findings suggest that the awareness of the risks associated with AMR is relatively high and widespread. Continuous information transfer of the risks associated with animal health because of AMU and AMR development is important to ensure all stakeholders are aware of the consequences of antimicrobial misuse.

Scepticism within the livestock sector about the contribution of agriculture to AMR has been previously identified, especially in terms of the potential links between agricultural AMU and human health risks (Morris et al., 2016; Etienne et al., 2017). In line with previous findings, this review found that the awareness of the link between AMR in agriculture and humans was low in the $20 \%$ of studies exploring the topic. Despite many South Carolina and Washington dairy farmers agreeing that AMR could occur in both humans and animals, there was a lack of concern that the overuse of antimicrobials or AMR in animals could threaten farm workers (Raymond et al., 2006; Friedman et al., 2007). Very few UK, Indian and Tennessee dairy farmers perceived the threat of AMR in humans as a result of AMU or AMR development in animals (Jones et al., 2015; Ekakoro et al., 2018; Kumar \& Gupta, 2018). Only two studies explored veterinarian's awareness of the link between AMR in humans and animals. Some Dutch veterinarians were motivated to reduce their AMU for public health reasons, while others doubted a significant contribution from veterinary AMU to AMR in humans (Speksnijder et al., 2015). Most Canadian dairy veterinarians disagreed on some level that AMU in dairy cattle contributes to resistance in human medicine (Léger et al., 2015). This suggests that despite many farmers and veterinarians having an awareness of some of the 
potential risks associated with AMR, there is a belief amongst many that the overuse of antimicrobials in agriculture does not impact on the development of AMR in humans. To overcome this, evidence-based information relating to the link between AMU and AMR in livestock and AMR in human medicine should be promoted to both farmers and veterinarians, to improve their understanding and encourage more prudent AMU.

These findings show that although some farmers and veterinarians know AMR can occur in humans and animals, many do not perceive a risk to human health as a result of agricultural AMU. The gap between knowledge and behavior suggests that they hold competing beliefs about what constitutes appropriate use, this can be considered a form of cognitive dissonance (Festinger, 1957) and highlights the need for increased education of farmers and veterinarians on the need for prudent AMU. It is important that awareness raising campaigns are targeted at dairy farmers and veterinarians globally to improve AMR understanding and promote consistent prudent AMU. Academic research in the field should be translated to farmers and veterinarians in a relatable manner and continuous transfer of AMR risk information relating to livestock is necessary, with emphasis on its link with human medicine.

\section{Theme 2: Determinants of farmer and veterinarian's $A M U$ practices}

Reasons for AMU in the dairy sector. Previous literature has shown mastitis to be the most frequently occurring disease in dairy cows (Ruegg, 2017) and the most prevalent reason for antimicrobial prescription in dairy cattle (DeBriyne, 2014). This review confirmed these findings as the majority of dairy farmers and veterinarians indicated that their most common reason for AMU was as a result of mastitis in the eight studies exploring reasons for AMU. The majority of veterinarians studied in Denmark, Portugal and Sweden, and dairy farmers studied in the UK, USA, Denmark and Sweden agreed that mastitis is the most common reason for AMU on dairy farms (Vaarst et al., 2003; Raymond et al., 2006; Jones et al., 2015; 
Kayitsinga et al., 2017; Carmo et al., 2018, Ekakoro et al., 2018; Higham et al., 2018; Fischer et al., 2019). Respiratory infections such as pneumonia (Jones et al., 2015; Ekakoro et al., 2018; Fischer et al., 2019), lameness and hoof problems were also noted as common reasons for dairy farm AMU (Raymond et al., 2006; Ekakoro et al., 2018, Fischer et al., 2019). Whilst antimicrobials are used to treat a number of conditions in dairy cattle, AMU is linked more significantly to mastitis. In order to overcome this, education of farmers and veterinarians on the prevention and management of mastitis without or with minimal AMU is necessary including strategies such as selective dry cow therapy (SDCT), whereby cows with a low probability of an intramammary infection do not receive antibiotics (Kabera et al., 2020).

The use of antimicrobials for disease prevention in addition to therapeutic use has been argued in other veterinary contexts (Coyne et al., 2016). Three studies within this review explored prophylactic AMU. Many Italian veterinarians stated that they administered antimicrobials before the onset of mastitis $(62 \%)$ more often than before the onset of respiratory diseases signs (28\%) (Busani et al., 2004). Peruvian dairy farmers and Dutch veterinarians also reported some prophylactic AMU although they advised that their use was primarily therapeutic (Redding et al., 2014; Speksnijder et al., 2015). These findings suggest that prophylactic AMU is uncommon in dairy farming. However, it should be noted that very few studies within this review reported on such use and so findings may not be applicable to the wider dairy sector. It is important to note that farmers may be apprehensive to fully disclose the degree to which they prophylactically use antimicrobials as a result of bias. Future research should explore prophylactic use further to obtain a clearer idea of the level at which such use occurs in dairy cattle.

Farmer treatment choice factors. Antimicrobials play a crucial role in veterinary medicine to maintain animal health and welfare (FAO, 2016; Hudson et al., 2017) and so it is unsurprising that animal welfare has previously been highlighted as a driver of AMU in other 
agricultural sectors (Lhermie et al., 2019). The importance of animal welfare in deciding on AMU was confirmed within this review by three studies of dairy farmers from the UK, USA, and Denmark (Vaarst et al., 2003; Jones et al., 2015; Ekakoro et al., 2018; Golding et al., 2019). Farmers in other livestock sectors have previously reported that they have adequate knowledge of their animal's behavior and the ability to identify abnormalities which indicate the presence of disease (Landfried et al., 2018). Within this review, previous experience and ability to accurately judge their animal's health when deciding on treatment options were reported to influence AMU decision making in four studies by many famers from Germany, the Netherlands, New Zealand and USA (Raymond et al., 2006; Swinkels et al., 2015; McDougall et al., 2017; Ekakoro et al., 2018).

Previous literature stated that farmers rely strongly on their veterinarian for advice (Lathers, 2001) and recommendations have been made that farmers should rely on knowledgeable veterinarians to make accurate treatment decisions based on credible examinations of their animals (Ruegg, 2006). The impact of veterinary advice on farmer decision making varied between the six studies which explored the topic within this review. Farmers studied in the Netherlands, New Zealand, Peru and USA (Michigan, Minnesota, New York \& Wisconsin) reported that veterinary recommendation is the most important factor in their decision making process (Zwald et al., 2004; Redding et al., 2014; Swinkels et al., 2015; McDougall et al., 2017), while less than half of the dairy farmers studied in Malaysia and Pennsylvania routinely seek veterinary advice or prescription prior to antimicrobial administration (Sawant et al., 2005; Sadiq et al., 2014).

Other factors influencing farmer AMU decision making within this review included drug attributes such as perceived efficacy of medicines, withdrawal times and cost (Redding et al., 2014; Ekakoro et al., 2018) ensuring profitability and financial safeguarding (Jones et al., 2015; Golding et al., 2019), specific cow characteristics (Vaarst et al., 2002; Vaarst et al., 
2003), culture and sensitivity testing (Ekakoro et al., 2018) and recommendations of other farmers (Swinkels et al., 2015).

The variety of reported influences on farmer behaviour within this review suggests that farmer decision making is not always straightforward and depends on individual situations as well as potentially their working relationship with their veterinarian. It is important to note that within the scope of this review not all studies explored the reasoning behind farmers AMU in the same way, therefore future research should consider investigating such factors further.

Determinants of veterinarians prescribing practices. Clinical factors such as disease signs, antimicrobial susceptibility and predicted treatment outcomes have been found to motivate antimicrobial prescribing decisions in human medicine (Coenen et al., 2002, Teixeira Rodrigues et al., 2013). Many veterinarians from five studies within this review confirmed that this plays an integral part in antimicrobial prescribing in livestock with many ideally basing their treatment decision on the specific clinical situation. Prior to prescribing it is vital for many veterinarians to perform a physical examination of the animal (Redding et al., 2013; Chauhan et al., 2018; Golding et al., 2019). Understanding farm disease history and treatment response is also considered by many veterinarians (Cattaneo et al., 2009; Redding et al., 2013; McDougall et al., 2017; Golding et al., 2019).

Antimicrobial characteristics have been reported to motivate antimicrobial prescribing decisions in human medicine (Coenen et al., 2002, Teixeira Rodrigues et al., 2013). Three studies within this review reported that drug attributes influence veterinarian's decisionmaking. Drug efficacy, withdrawal time and ease of administration are considered by some Canadian, Dutch and UK veterinarians when prescribing antimicrobials (Léger et al., 2015; Speksnijder et al., 2015; McDougall et al., 2017). Veterinarians perceptions of farmers 
knowledge and abilities were considered by UK \& Peruvian veterinarians (Redding et al., 2013; Golding et al., 2019). Profit was not commonly considered by the veterinarians within this review when deciding on treatment options, some Canadian and Dutch veterinarians felt that veterinarian profit is no longer a driver for antimicrobial prescription within the dairy sector (Léger et al., 2015; Speksnijder et al., 2015).

Veterinarians perceptions of their client's willingness or ability to pay for treatment and how compliant they would be in administering the treatments, have been found to influence veterinary prescribing outside of the dairy sector (Mateus et al., 2014). Within this review it was reported by veterinarians in three studies that farmers often influence their decision making. Some veterinarians in the UK and Kenyan admitted that they sometimes fulfil treatment requests of farmers to avoid upsetting them (Higham et al., 2016; Higgins et al., 2017) and some Canadian veterinarians dispensed antimicrobials over the counter to regular clients more often (Léger et al., 2015).

It should be noted that within this review studies exploring the decision making of veterinarians for prescribing antimicrobials within the dairy sector were scarce. The most common influencer of veterinarian's decision making reported within this review was the individual clinical situation and perceptions of the farmer. Future research should explore how veterinarians can build better relationships with their clients so that they can focus on the individual clinical situation as opposed to concerns of upsetting farmers.

\section{Theme 3: Barriers and facilitators to reduced antimicrobial use in the dairy sector}

Barriers to reduced $\boldsymbol{A M U}$. Deciding whether to continue or withdraw antimicrobial treatment was found to be problematic for many farmers and veterinarians within this review, due to the unpredictable nature of disease and the potential cost of disease returning when antimicrobials are discontinued. Such concerns are also common within pig production 
376 (Sheehan et al., 2013). Economic constraints such as the cost of disease and changes in farm

377 structures to achieve reduced AMU were reported within six studies as limitations in Dutch,

378 Swedish, Irish, UK and US studies (Raymond et al., 2006; Friedman et al., 2007; Speksnijder

379 et al., 2015; Magalhaes Sant'Ana et al., 2017; Fischer et al., 2019; Golding et al., 2019).

380 Some farmers in the USA suggested that veterinarians are not always consulted for AMU

381 advice due to their fees (Friedman et al., 2007) while others reported they have previously

382 been concerned that milk production would reduce if antibiotics were not used for dry-cow

383 treatment (Raymond et al., 2006). Prophylactic AMU was considered necessary by some

384 Dutch veterinarians, arguing that if certain infections were not prevented, they could result in 385 increased mortality and financial loss (Speksnijder et al. 2015). These findings suggest that many farmers and veterinarians are concerned that reduced AMU may come with economic risks. Further research should focus on how economic risks of reducing AMU can be minimised.

Previous findings suggest that having a productive farm and taking good care of their animals are important to farmers and central to how they conceptualise a good farmer (Wilkie, 2005; Bock et al., 2007, Ellis, 2014, Shortall et al., 2018). This was confirmed by six studies within this review, farmers and veterinarians reported animal welfare as a barrier to reducing AMU. There was concern amongst farmers and veterinarians in the UK that reductions could inhibit their ability to treat sick animals and maintain animal welfare (Golding et al., 2019). Farmers studied in France and the UK feared that no antibiotic cover would lead to severe mastitis and death (Orpin, 2007; Poizat et al., 2017). Dutch farmers and veterinarians were unsure whether a cow would recover without antimicrobials (Scherpenzeel et al. 2016; Scherpenzeel et al. 2018) and many Dutch veterinarians reported it is their duty to treat diseased animals for reasons of animal welfare, regardless of the issue of AMR (Speksnijder et al. 2015). Despite these findings, research in the UK dairy sector found that ceasing the use of the highest 
401

402

403

404

405

406

407

408

409

410

411

412

413

414

415

416

417

418

419

420

421

422

423

424

425

priority critically important antimicrobials can occur while maintaining herd health and farm productivity (Turner et al., 2018). These findings highlight the responsibility to animal welfare felt by farmers and veterinarians; thus they feel that antimicrobials are essential to preserve animal welfare and productivity. Further education on the efficacy of alternative practices to reduce AMU, may build confidence in their ability to maintain animal welfare while reducing AMU.

Time constraints and labor burden were commonly noted as barriers to reduced AMU within five studies (Friedman et al., 2007; Speksnijder et al. 2015; Scherpenzeel et al. 2016; Poizat et al., 2017; Golding et al., 2019). Some South Carolina farmers reported not having time to wait for a veterinarian to make a farm visit as they need to make quick judgements to avoid infection spread (Friedman et al., 2007). Selective antimicrobial treatments were seen by many Dutch and French farmers as requiring additional work (Scherpenzeel et al. 2016; Poizat et al., 2017) and some Dutch veterinarians agreed that such treatment is generally more labor intensive than mass medication and so it can be difficult to convince farmers to adopt such practices (Speksnijder et al. 2015). Despite a desire to make greater use of diagnostic testing and an appreciation for its importance to reduce AMU, many veterinarians felt that it is often impractical due to delays in obtaining results (DeBriyne et al., 2013; Coyne et al., 2016; Golding et al., 2019; ) and is sometimes only used by Dutch, Indian and UK veterinarians when initial treatments are unsuccessful (Speksnijder et al., 2015; McDougall et al., 2017; Chauhan et al., 2018). These findings suggest that when considering interventions and promoting reduced AMU, labor and time requirements should be considered to ensure successful implementation.

Pressure from farmers to prescribe antimicrobials is often highlighted in studies investigating the prescribing behaviours of veterinarians in a range of veterinary contexts (DeBriyne et al., 2013, Gibbons et al., 2013; McIntosh and Dean, 2015; Coyne et al., 2016). This was 
confirmed in this review with many veterinarians in two studies reporting that pressure from

427 farmers can limit their efforts to reduce AMU. Some Dutch veterinarians felt pressure to prescribe antimicrobials and sometimes have difficulty persuading farmers to reduce AMU

429 (Speksnijder et al. 2015). Within this review some UK veterinarians reported that it is 430 sometimes difficult to prioritize responsible AMU due to conflicts of interest and fear of upsetting farmers (Higgins et al., 2017). Findings in other veterinary contexts have shown that some veterinarians are more influenced by social expectations than scientific reasoning, acting upon client pressures to prescribe even when they felt antimicrobials were unnecessary. This prescribing behavior has also been observed with human antibiotic prescribing practices (Paredes et al., 1996; Tonkin-Crine et al., 2011; Broom et al., 2014; Hockenhull et al., 2017; Smith et al., 2018). Veterinarians have previously been advised to adopt new communication styles and overcome the assumptions they may have about farmers in order to ensure engagement with them on disease prevention and antimicrobial stewardship (Jansen et al., 2010). Although perceptions of farmers were highlighted by many veterinarians within this review as influencing prescribing practices and often limiting their efforts to reduce AMU, not many explicitly identified this as a barrier to reducing AMU. Despite similar findings being reported in other veterinary contexts regarding farmer pressure as a barrier to reduced AMU, such literature in the context of dairy farming is limited and so may be worth focus from future research.

Some Dutch veterinarians noted that high on farm AMU may be due to insufficient skills of farmers in terms of disease detection and recommended practices (Speksnijder et al. 2015).

447 Irish veterinarians acknowledged that farmers generally have little awareness of the connection between their husbandry practices and AMR in human medicine, suggesting that until this is understood, farmer behavior will not change (Magalhaes Sant'Ana et al., 2017).

450 Despite this being highlighted as a barrier to reduced AMU within this review it cannot be 


\section{DAIRY ANTIMICROBIAL USE: A SYSTEMATIC REVIEW}

451

452

453

454

455

456

457

458

459

460

461

462

463

464

465

466

467

468

469

470

471

472

473

474

assumed as the view of all veterinarians due to the small number of studies exploring veterinarians perceptions of farmers skills and knowledge as a barrier to reduced AMU.

Future research is needed to determine whether this is a common attitude of veterinarians dealing with dairy farmers.

Other barriers reported included social constraints (Fischer et al., 2019), industry pressure (Golding et al., 2019), low risk perception (Higgins et al., 2017), scepticism of antimicrobial alternatives (Vaarst et al., 2003) and the fact that antimicrobial treatments are effective and convenient (Poizat et al., 2017). These findings were not as commonly reported however should still be given consideration in attempts to reduce AMU and perhaps deserve attention in future research.

These findings show farmers and veterinarians consider numerous factors to be barriers to reducing their AMU in dairy cattle. Economic constraints, animal welfare, structural limitations (time constraints and labor requirements), individual attitudes to AMR, pressure felt by veterinarians from farmers as well as veterinarians' perceptions of farmers are commonly reported barriers to reduced AMU. To overcome the main barriers identified by this review future research should explore how AMU can be reduced with minimal economic risk, promoting the efficacy of alternative practices while maintaining animal welfare and how pressure felt by veterinarians from farmers can be reduced. From these findings it is recommended that interventions aimed at reducing AMU consider the labor and time requirements, as well as providing the skills and knowledge necessary to efficiently achieve reductions.

Facilitators of reduced AMU. Previous research suggests herd management and improved biosecurity as a cost effective and feasible approach to disease prevention, and alternative to reliance on routine AMU (Postma et al., 2015; Rojo-Gimeno et al., 2016). 
475 Improved biosecurity and management practices have been associated with reduced AMU in

476 pig production (Lannen et al., 2013; Arnold et al., 2016; Postma et al., 2016). On farm management measures and disease prevention controls were welcomed by many farmers and veterinarians from eight studies within this review as facilitators of reduced AMU. Disease

479 prevention with consistent health management practices was considered important by veterinarians studied in Denmark, Portugal, Switzerland, and the USA (Cattaneo et al., 2009; Speksnijder et al. 2015; Carmo et al., 2018). Similarly, many Indian, Swedish, Dutch and American dairy farmers agreed that practices such as proper nutrition, housing, breeding and infection control were important to reduce AMU (Ekakoro et al., 2018; Holstege et al., 2018; Kumar and Gupta, 2018; Fischer et al., 2019). Vaccinations are also seen by some farmers and veterinarians as a method of reducing AMU (Cattaneo et al., 2009, Ekakoro et al., 2018) and it is seen as a cost-effective strategy to control the spread of AMR by Indian farmers (Kumar and Gupta, 2018). On farm diagnostic testing is considered a facilitator of reduced AMU by Irish veterinarians (Magalhaes Sant'Ana et al., 2017) and some Tennessee dairy farmers reported that such testing has previously led to a reduction in AMU (Ekakoro et al., 2018). Correct diagnostic processes and early disease detection are considered important by some US dairy farmers and Dutch veterinarians to avoid unnecessary AMU (Speksnijder et al. 2015; Ekakoro et al., 2018). This suggests that many farmers and veterinarians within this review and potentially outside its scope, see improved herd management and biosecurity measures as important steps to reduce AMU while maintaining productivity and animal welfare and should be promoted to encourage behavior change. their efficiency in reducing AMU (Visschers et al., 2016). Programs aimed at increasing awareness of AMU and AMR are hypothesised to contribute to a reduction in agricultural antimicrobial sales (Carmo et al., 2017). Relevant and targeted information is considered vital 
500

501

502

503

504

505

506

507

508

509

510

511

512

513

514

515

516

517

518

519

520

521

522

523

524

when aiming to alter behavior and for the targeted population to pay attention to information, it is important that education is tailored to their needs and knowledge (Kreuter et al., 2019).

Within this review, training and education was considered important by farmers and veterinarians to facilitate reduced AMU within five studies. Some UK veterinarians felt that farmers having the skills to implement selective therapy facilitates reduced AMU (Higgins et al., 2017) and the need for additional farmer training on infection prevention and control was supported by some Tennessee dairy farmers to reduce AMU (Ekakoro et al., 2018). Many veterinarians studied supported increased veterinary education on prudent AMU and alternative practices to promote their use amongst clients and facilitate reduced AMU (Magalhaes Sant'Ana et al., 2017; Poizat et al., 2017; Carmo et al., 2018). The review findings suggest that education of farmers and veterinarians is fundamental in the fight against imprudent AMU in dairy cattle. Combined with the desire for increased knowledge relating to AMU and AMR, expressed by farmers within this review, this highlights its importance and potential to help facilitate reduced AMU.

The potential economic rewards of profitability and reduced costs have been reported as the most important driver of AMU behavior change in pig farming (Visscher et al., 2015). Some Dutch veterinarians were concerned that higher tariffs for their services would decrease farmers' motivation to consult them and so they consider low tariffs essential for animal health and appropriate AMU (Speksnijder et al. 2015). To reduce farm AMU, it has been suggested that farmers and veterinarians should be incentivised to make reduced AMU more salient in their day to day operations, perhaps by using financial incentives such as those recently used in the English national health service (Islam et al., 2018). Some Indian veterinarians were concerned by the lack of incentive for farmers withholding antimicrobial treated milk, stating that withholding should be incentivised to prevent antimicrobial tainted milk entering the food chain (Chauhan et al., 2018). Within this review such financial 
facilitators to reduced AMU were confirmed by farmers and veterinarians. In the

Netherlands, some noted 'financial consequences' as one of the most positive aspects of reducing AMU (Scherpenzeel et al. 2016) and some French veterinarians stated that they have highlighted the cost benefit of alternative medicines to farmers to promote reduced AMU (Poizat et al., 2017). These findings suggest that many farmers and veterinarians see economic rewards for reducing AMU as having the potential to facilitate and encourage behavior change. As economic burden has been highlighted within this review as a barrier to reduce AMU, promoting the evidence that farms can remain productive and profitable while reducing AMU is necessary.

It has been reported that there may be scope for veterinarians to take on a more proactive role in promoting preventative medicine to farmers, in order to reduce AMU (Higgins et al., 2013). Within this review some farmers highlighted the role their veterinarians could play in reducing AMU. Dutch farmers felt that veterinarians could help facilitate change as they are their main advisors and encouragers of reduced AMU (Scherpenzeel et al. 2016) and UK farmers also expressed a desire for guidance from their veterinarians to reduce AMU due to the support and motivation they provide (Golding et al., 2019). These findings, although limited within the scope of this review, coupled with many farmers reporting the key role of veterinarians in their decision making, suggests that veterinarians can play a pivotal role in promoting AMU reduction.

Improved policy and regulation of AMU in livestock was deemed necessary by Irish and Indian veterinarians within this review to reduce AMU (Magalhaes Sant'Ana et al., 2017; Chauhan et al., 2018). Some veterinarians from Denmark, Portugal and Switzerland also advised that mandatory interventions applied by national or international authorities have appeared to work best in reducing AMU in the past (Carmo et al., 2018) and many Dutch veterinarians felt that policies to reduce AMU should be equal in all countries to maintain a 
550

551

552

553

554

555

556

557

558

559

560

561

562

563

564

565

566

567

568

569

570

571

572

573

fair, competitive market and prevent illegal antimicrobial trade (Speksnijder et al. 2015). UK farmers reported that they see government and industry bodies as having the resources and expertise to conduct research and produce evidence-based guidelines to facilitate reduced AMU (Golding et al., 2019). This suggests that farmers and veterinarians would be accepting of evidenced based policies and regulations being introduced or revised to reduce AMU. It is suggested that many veterinarians and farmers would be open to regulations being harmonised in all countries, but this would need to be a potential focus for future research due to the limited findings within this review.

These findings show that numerous factors are perceived by farmers and veterinarians as having the potential to facilitate reduced AMU. From these findings future research recommendations include the promotion of herd health management and biosecurity measures, coupled with improved education of farmers and veterinarians on alternative practices to increase their confidence in their ability to reduce AMU. Promotion of evidence that farms can remain productive and profitable with reduced AMU is necessary to overcome this uncertainty which exists amongst some farmers and veterinarians. Findings suggest that veterinarians can play a pivotal role in promoting reduced AMU and that harmonisation of regulations and policy regarding AMU should be considered by future research as ways in which AMU in the dairy industry can be improved.

\section{Theme 4: Farmer and veterinarians' responsibility to $A M R$ and desire to reduce $A M U$}

Prudent use of antimicrobials in livestock is reported to be the responsibility of veterinarians and farmers and so both need to be aware of the impact their AMU can have (Reyher et al., 2017). Within this review, $60 \%$ of studies reported on farmer and veterinarians perceived responsibility to AMR. Some UK farmers expressed ownership for improving AMR (Golding et al., 2019) while of the Malaysian farmers studied, their role in tackling AMR was 
574

575

576

577

578

579

580

581

582

583

584

585

586

587

588

589

590

591

592

593

594

595

596

597

598

perceived as more important by those with a larger herd size (Sadiq et al., 2018). Dairy farmers studied in Germany and the Netherlands felt that meat-producing farmers were responsible for agricultural AMR (Swinkels et al., 2015) and some UK and Malaysian famers considered veterinarians responsible for managing the emergence of AMR (McDougall et al., 2017; Sadiq et al., 2018). Research has found that this external attribution of responsibility to others is a major barrier to behavioral change and must be understood, accounted for and managed in policy development (Ruegg et al., 2017). These findings suggest that not all farmers recognise the role they play in the development and spread of AMR.

Previous literature advised that enabling behavioral change requires farmers and veterinarians to perceive their own personal roles and actions as efficacious and important in relation to AMR (Fishbein and Cappella, 2006). Within this review many UK and Irish veterinarians acknowledged their responsibility to prescribe appropriately and have a sense of ownership in promoting reduced AMU (Magalhaes Sant'Ana et al., 2017; Golding et al., 2019). Some US veterinarians believe that many individuals including themselves contribute to AMR (Cattaneo et al., 2009) and while many Dutch veterinarians appeared to be motivated to reduce veterinary AMU for public health reasons, others doubted the contribution their use has on human health (Speksnijder et al. 2015). These findings suggest that although some veterinarians perceive their role in AMR as important, further education to consider their own practices as important to mitigate the spread of AMR is needed.

Many Dutch, UK and US farmers agreed that it is important to reduce AMU (Jones et al., 2015; Scherpenzeel et al. 2016; Kayitsinga et al., 2017). Some UK farmers felt that people in the industry would respect them for reducing their AMU (Jones et al., 2015) and Dutch farmers felt they could still be a good farmer while using less antimicrobials (Scherpenzeel et al. 2016). Some Dutch veterinarians also agreed that it is important to restrict livestock AMU, many trusting that they can be a good veterinarian and farmers can still be good farmers with 
599

600

601

602

603

604

605

606

607

608

609

610

611

612

613

614

615

616

617

618

619

620

621

622

623

less AMU (Scherpenzeel et al. 2018). These findings suggest that farmers and veterinarians are motivated by being considered "good" by their peers and industry colleagues by

conforming to the social norms of the industry, which may facilitate reduced AMU. Within the scope of this review, few studies were found that focused on the opinion of others as a facilitator to reduced AMU and so may be considered by future research.

Previous literature stated that veterinarians and farmers are not always aware of the public health risks associated with extensive agricultural AMU and so do not always feel responsible for the problematic outcomes, lowering their motivation to change their behavior (Coyne et al., 2016; Ritter et al., 2017; Visschers et al., 2016). The perceived ability to reduce AMU varied amongst farmers within this review. Many UK and US farmers felt they had the ability to reduce AMU (Higham et al., 2018; Vasquez et al., 2019) and some Swedish farmers admitted they could make more effort to reduce AMU (Fischer et al., 2019). Dutch and French farmers felt reducing their AMU could be difficult and despite many veterinarians feeling a responsibility to tackle AMR, some still consider prophylactic AMU necessary to safeguard animal welfare (Speksnijder et al. 2015; Poizat et al., 2017). These findings show that the perceived ability of farmers and veterinarians to reduce AMU is varied, combined with the concern and uncertainty associated with reduced AMU reported within this review, reinforces the importance of education on alternative practices to enable farmers and veterinarians to confidently reduce their AMU.

Within this review dairy farmers in the UK and USA reported positive intentions towards prudent AMU (Jones et al., 2015; Vasquez et al., 2019), while farmers and veterinarians in Switzerland supported the proposal of voluntary programs to reduce AMU (Van den Borne et al., 2017). Another study of Dutch veterinarians also reported a positive attitude towards policy change to reduce AMU (Scherpenzeel et al. 2018). Previous literature recommended that shared responsibility between farmers and veterinarians may help behavior change as 
624

625

626

627

628

629

630

631

632

633

634

635

636

637

638

639

640

641

642

643

644

645

646

647

there is evidence that farmers intentions to change is reinforced by mutual support from their major referents which includes veterinarians and other advisors (Ellis-Iversen et al., 2010).

These findings suggest that the intentions of many farmers and veterinarians towards reducing AMU within the dairy sector may be primarily positive. This could be beneficial for the introduction of policy and programs designed to reduce AMU. Further research is however necessary to reinforce this finding.

Based on these findings it is recommended that there is a focus on improving the education of farmers and veterinarians so that they recognise the role their AMU practices can have on AMR in both veterinary and human medicine, in order to heighten the responsibility they feel towards the issue. There is also scope for research into how peers and colleagues of farmers and veterinarians within the dairy industry can act as motivators to their desire to reduce AMU.

\section{Theme 5: The importance of the farmer-veterinarian relationship dynamic in reducing} $A M U$

Just over $50 \%$ of the studies included in this review reported on the farmer-veterinarian relationship and the role it may play in AMU within the dairy sector.

Communication and information transfer between farmers and veterinarians. It has been reported by several studies that veterinarians are farmers preferred information source for general farming practices (Garforth et al., 2013) and AMU guidance (Visschers et al., 2015, Visschers et al., 2016). Within this review the relationship and communication with veterinarians were valued highly by many Dutch, German, UK and US farmers, with veterinarians often identified as their most credible, reliable and influential AMU and AMR information sources (Friedman et al., 2007; Jones et al., 2015; Swinkels et al., 2015; Kramer et al., 2017; Golding et al., 2019). Some Dutch, German and US farmers consider 
veterinarians to be the most important information source for mastitis (Swinkels et al., 2015;

Kayitsinga et al., 2019) and veterinary recommendation and advice is considered by some Peruvian, Dutch and UK farmers as their most important decision making factor (Redding et al., 2014; Scherpenzeel et al. 2016; McDougall et al., 2017). Some Swedish farmers highlighted the importance of a good relationship with their veterinarian, despite this many reported that they only call on them when they are sure they cannot cure the animal themselves (Fischer et al., 2019). Many Peruvian, UK and US famers do not always seek the advice of their veterinarian before administering antimicrobials (Redding et al., 2014; Jones et al., 2015; Sawant et al., 2007). It could be suggested from these findings that despite many farmers perceiving their veterinarians as credible and important information sources they do not always seek their advice which may be linked to the findings within this review that some farmers feel veterinary fees are too expensive.

Veterinarians' communication experiences with farmers varied within this review. Many Indian veterinarians reported that by the time a farmer seeks their help they have already tried many unsuccessful treatment strategies (Chauhan et al., 2018). Despite this many Dutch veterinarians reported that providing advice to farmers is increasingly becoming part of their daily work (Speksnijder et al. 2015). One-on-one meetings between veterinarians and farmers are considered by many US veterinarians as the most effective way to educate farmers on AMR (Cattaneo et al., 2009). Despite a desire to educate farmers, it was reported that some

667 Canadian veterinarians are more likely to dispense antimicrobials over the counter to clients they have regular contact with as opposed to those who they rarely meet with (Léger et al., 2015). These findings suggest that many veterinarians have a desire to provide advice and education to farmers however some acknowledge that they are not always farmer's first point

671 of contact. It could be suggested that veterinarians have the ability to guide farmers in 
reducing their AMU and encouraging them to utilise veterinary services more frequently may help tackle antimicrobial misuse.

Farmer and veterinarians' perceptions of each other. Previous literature highlighted the need to communicate the importance of restrictive AMU through information channels which farmers perceive to be trustworthy (Ritter et al., 2017). Within this review many Swedish and UK farmers trusted their veterinarians' AMU information and recommendations (Ekakoro et al., 2018; Fischer et al., 2019; Golding et al., 2019). Some Swedish farmers expressed a desire for a trust-based dialog with their veterinarian, they want their veterinarians to trust in their farming competence and abilities as much as farmers trust in their medical expertise (Fischer et al., 2019). Veterinarians' perceptions of their client's compliance have been reported previously as a common non-clinical factor influencing antimicrobial prescribing decisions, this influence has also been reported in human medicine (Teixeira Rodrigues et al., 2013; Coyne et al., 2016). Some Peruvian veterinarians admitted that their perception of farmers' education level and ability to understand drug attributes and pathogens sometimes influenced their prescribing (Redding et al., 2013). Although many UK veterinarians felt farmers follow their treatment advice some advised that if they were concerned a farmer would not adhere, they would account for this when prescribing (Golding et al., 2019). Dutch veterinarians reported that as they are only able to make recommendations to prevent disease with no way of enforcing it, they often experienced feelings of frustration with farmers because when a farmer did not follow their advice, they were again confronted with sick animals (Speksnijder et al. 2015). Existing literature advises that generally, veterinarians are perceived as trustworthy referents for farmers therefore it is postulated that they act as the main information source on prudent AMU (Ellis-Iversen et al., 2010, Speksnijder and Wagenaar, 2018). These review findings suggest that farmers trust in their veterinarians for advice however some may desire that the trust is reciprocated by the 


\section{DAIRY ANTIMICROBIAL USE: A SYSTEMATIC REVIEW}

697

698

699

700

701

702

703

704

705

706

707

708

709

710

711

712

713

714

715

716

717

718

719

720

721

veterinarians. This highlights the importance of two-way trust between farmers and veterinarians and future research to increase this could improve their relationship and AMU practices.

Within this review some UK veterinarians perceived differences in farmers' personalities, occasionally influencing their prescribing decision and willingness to raise the topic of antimicrobial stewardship. They sometimes prescribed antimicrobials to prevent awkward situations noting that it takes time to develop effective relationships with farmers (Higgins et al., 2017; Golding et al., 2019). Dutch and UK veterinarians were sensitive to the financial pressures they feel farmers face, leaving them limited in their ability to help and hesitant to increase their service tariffs (Speksnijder et al. 2015; Golding et al., 2019). This suggests that not all farmers are perceived equally by veterinarians and such perceptions depend on the relationship they have with their clients. Farmers and veterinarians' perceptions of each other may be contributing to difficulties in reducing AMU and so future research should explore this further.

Many Dutch veterinarians perceived that farmers are accustomed to raising their animals with antibiotics (Speksnijder et al., 2015), and client habits were noted by Peruvian veterinarians as a determinant of prescribing (Redding et al., 2013). Some Indian and UK veterinarians perceived farmers as reluctant to change their behavior and considered changing farmers AMU a challenge (Chauhan et al., 2018; Golding et al., 2019; Higgins et al., 2019).

Relatively new commercial dairy farmers were found by some Indian veterinarians to be more open to modifying practices (Chauhan et al., 2018) and many UK veterinarians believe that a key part of their role is to better educate farmers and believe that engaging with a farmer and understanding their needs can impact on farmer behavior (Golding et al., 2019). This suggests that according to many veterinarians, achieving behavior change amongst dairy 
farmers is difficult. Future research should utilise behavior change theory in an effort to determine evidence-based interventions and strategies which can be aimed at both farmers and veterinarians to achieve reduced AMU.

Collaboration between veterinarians and farmers. Research suggests that the reduction of AMU requires participation from all stakeholders responsible for administering antimicrobials including veterinarians, producers, and animal handlers (Salisbury et al., 2002). Better animal health outcomes may be achieved by collating expert opinions, the use of multi-disciplinary teams in human healthcare has been shown to improve patient outcomes (Hickman et al., 2016, Mudge et al., 2016). Within this review, encouraging collaborative work between veterinarians and farmers was considered an important strategy for improving antimicrobial stewardship by some UK farmers and veterinarians (Golding et al., 2019). A collective responsibility amongst stakeholders was also seen by Irish veterinarians as having the potential benefit of limiting individual stakeholder ownership of the AMR problem (Magalhaes Sant'Ana, 2017). Despite a desire to work collectively, some UK farmers and veterinarians demonstrated frustrations towards other stakeholders and colleagues, as they felt that their behavior is sub optimal while others felt their own antimicrobial stewardship efforts are undermined by other stakeholders and differing practices globally (Golding et al., 2019). This other blaming (placing the blame for increased AMR and imprudent AMU on other parties) has been observed previously by stakeholders in both human and veterinary medicine (Labi et al., 2018; Nicholson et al., 2018). It has been suggested that at an individual level approach, increasing the use of inclusive, one health stewardship initiatives which target individual knowledge and motivations may overcome other blaming as both veterinarians and farmers can feel blamed and stigmatized by others for AMR (Fynbo and Jensen, 2018; Johnson et al., 2018). Despite the authors awareness that tackling AMR is a One Health priority encompassing a multisectoral approach (FAO/OIE/WHO, 2017) only the 
practices and opinions of dairy farmers and veterinarians are considered within the scope of this review. These findings suggest that farmers and veterinarians may be open to more collaborative working. It should be considered however that the relationship between farmers and veterinarians and its impact on AMU is not heavily focused on by many of the studies within this review and further research is needed to confirm findings.

Some Danish farmers admitted that although their veterinarians would like closer collaboration, their financial situation would not allow for increased veterinary services (Vaarst et al., 2003) while some Dutch veterinarians also acknowledged that low tariffs for veterinary services are needed to encourage farmers to utilize their services (Speksnijder et al. 2015). Evidence suggests that collaboration between farmers and veterinarians can be beneficial in developing antimicrobial stewardship plans on farms (Van Dijk et al., 2017) and drawing on a social identity approach could increase communication and collaboration between the groups (Jetten et al., 2017). Promoting the importance of a common fate can strengthen the shared social identity of stakeholders, and drive co-operation to achieving shared goals (Gaertner et al., 1993, Turner et al., 1994). Within this review farmers and veterinarians have identified each other as influencers of their decision-making processes and as having the ability to limit and facilitate reduced AMU. These findings make it credible that future research should focus on enabling farmers and veterinarians to work together confidently and effectively to achieve their common goal of reduced AMU on dairy farms.

This research has found that communication, individual perceptions, and trust in one another contribute to the working relationship between farmers and veterinarians. Certain aspects of these relationships have been highlighted by some as having the potential to limit or facilitate reduced AMU. Future research should aim to promote more frequent utilisation of veterinary services by farmers. Attempts to build the trust farmers and veterinarians have in one another 
is recommended in order to strengthen their relationships by overcoming inaccurate perceptions they may have of each other. Habits were highlighted as a potential reason why farmers do not always consult veterinarians for advice and so future research applying behavior change theory to farmer and veterinarian behavior is suggested to help overcome behavioral habits and result in reduced AMU. Overall it is suggested that future research into the relationship between farmers and veterinarians is necessary in order to highlight areas which can be targeted to strengthen their relationships and promote collaboration to enable them to work together effectively to reduce AMU.

\section{Strengths \& Limitations}

This research had a number of strengths and limitations. This review for the first time to the best of our knowledge systematically combined the existing literature exploring dairy farmers' and veterinarians' knowledge and awareness of AMR as well as their attitudes towards and perceptions of their AMU. This has extended previous research findings by summarising and comparing the literature from a broad range of study designs (interviews, surveys, focus groups), synthesised their primary findings and reviewed evidence supporting the findings. This review has identified potential links between previous study findings, providing scope for further research and potential avenues for promoting reduced AMU within the dairy sector. Despite the reasonable number of studies used in this review $(n=35)$, almost all were conducted in developed countries limiting the generalizability of the results on a global scale. The findings of the majority of studies were typically self-reported and so caution should be noted with regard to social desirability of the findings. The review has combined studies carried out over a broad period of time and so data reported by some of the studies may not necessarily reflect the current practices, attitudes, knowledge, and perceptions of participants. 
797 This review has identified gaps and scarcities in previous research investigating drivers of

798 AMU within dairy cattle. While many reasons for farmer's AMU have been highlighted

799 within this review, some factors although quoted less frequently may provide a deeper insight

800 into the motives behind farmer's AMU. The impact of herd size on farmer's perceptions of

801 their AMU practices and its contribution to AMR remains relatively unknown and so further

802 research in this area may provide a better indication as to how best to promote behaviour

803 change with specific farming groups. There is a need for further research investigating the

804 relationship dynamic between farmers and veterinarians and how it can be enhanced to implement reduced AMU on dairy farms. The perceptions farmers and veterinarians have of one another, in addition to the trust they have in each other remains relatively unexplored and

807 may provide key insights into just how much this relationship may influence on farm AMU. A deeper understanding of this relationship may help facilitate a collaborative effort between farmers and veterinarians to tackle the global issue of AMR by reducing their use of antimicrobials in dairy cattle.

812 Farmer and veterinarian's knowledge, awareness and perceptions of AMU and AMR vary within dairy farming. Increasing awareness of AMR may increase perceived responsibility to tackling AMR. Many factors determine the decision for AMU including animal welfare, time and labour requirements. Addressing the perceived barriers to reducing AMU may alter decision-making and reduce AMU. The relationship between farmers and veterinarians can

817 be a barrier or facilitator to prudent AMU depending on the perceived relationship dynamic.

818 As a trusted information source for farmers, veterinarians can educate farmers and promote reduced AMU. By altering perceptions of their clients, veterinarians may act as successful 
820

821

822

823

824

825

826

827

828

829

830

831

832

833

834

835

836

837

839

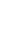

9

30

831

832

833

838 Farrell, Figure 1

antimicrobial stewards, while maintaining a good relationship with farmers. Many farmers and veterinarians are open to collaboration to achieve prudent AMU which is expected to create a shared responsibility of reducing AMU. Application of behavior change theory is expected to overcome barriers and elicit behavior change to achieve reduced AMU.

26

827
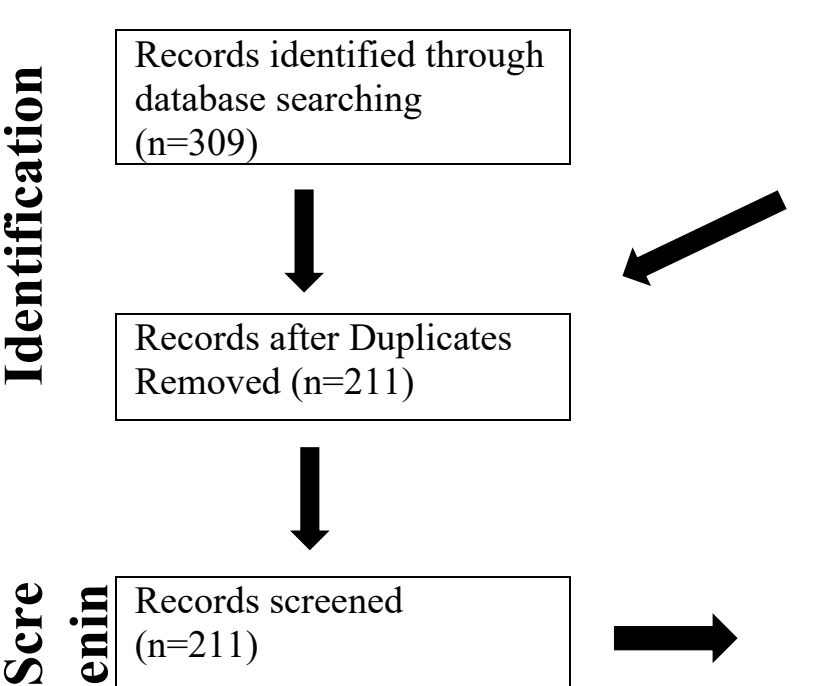

Additional records identified through other sources. $(\mathrm{n}=7)$

Records excluded based on title and abstract $(n=135)$

- Not a peer reviewed journal article $(n=13)$ 

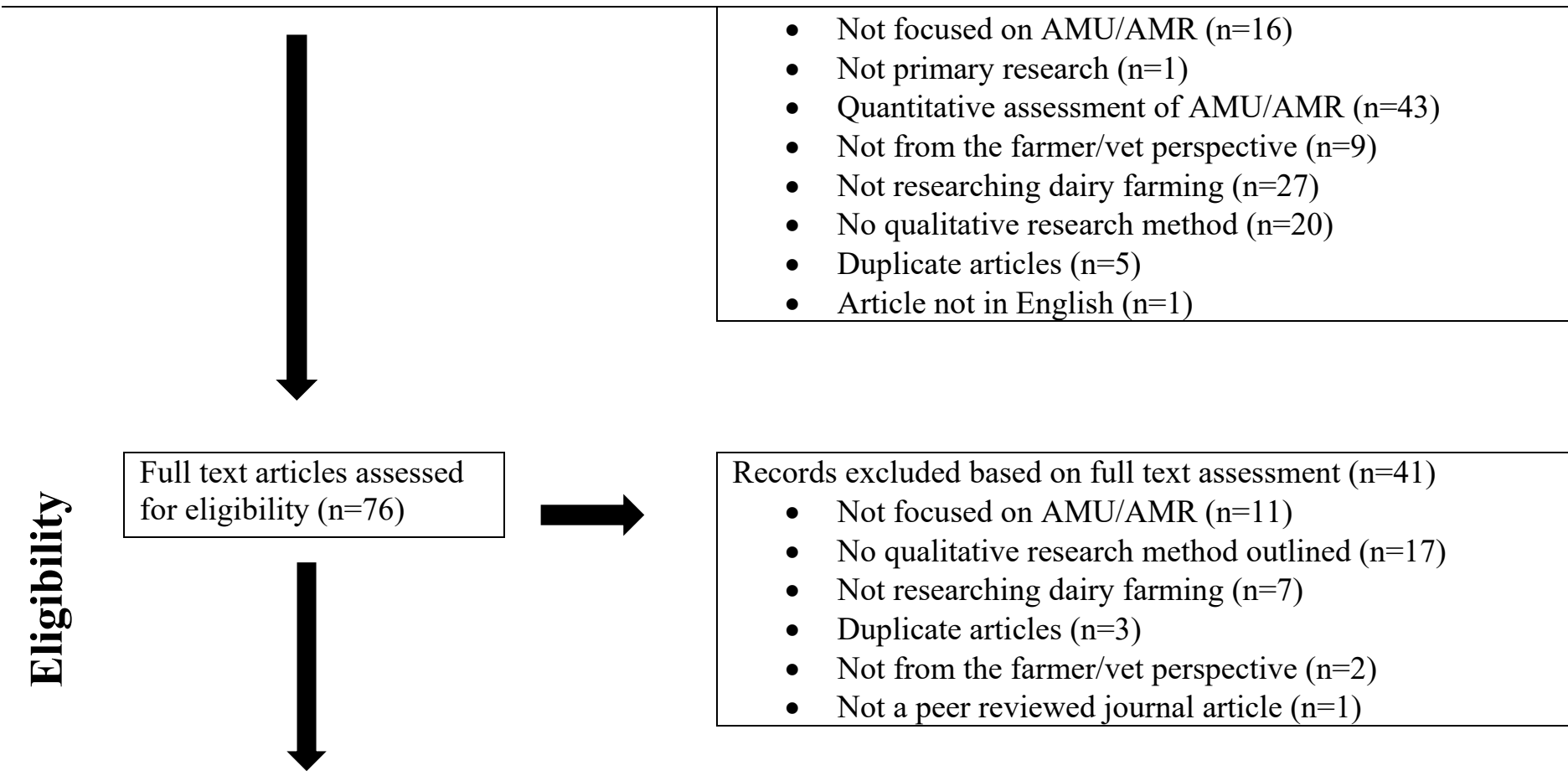

Records excluded based on full text assessment $(\mathrm{n}=41)$

- Not focused on AMU/AMR ( $\mathrm{n}=11)$

- No qualitative research method outlined $(n=17)$

- Not researching dairy farming $(\mathrm{n}=7)$

- Duplicate articles $(n=3)$

- Not from the farmer/vet perspective $(n=2)$

- Not a peer reviewed journal article $(\mathrm{n}=1)$

Studies included in systematic review $(\mathrm{n}=35)$

- Dairy Farmer studies $(\mathrm{n}=17)$

- Dairy Vet studies $(\mathrm{n}=3)$

- Dairy Farmer \& Vets $(n=3)$

- Various Vets inc. dairy $(\mathrm{n}=5)$

- Various Farmers inc. dairy $(n=3)$

- Multi stakeholder studies $(\mathrm{n}=4)$

Farrell, Figure 2 
DAIRY ANTIMICROBIAL USE: A SYSTEMATIC REVIEW

846

Data collection method

\begin{tabular}{|c|c|}
\hline Survey(n=19) & Interview(n=9) \\
\hline
\end{tabular}

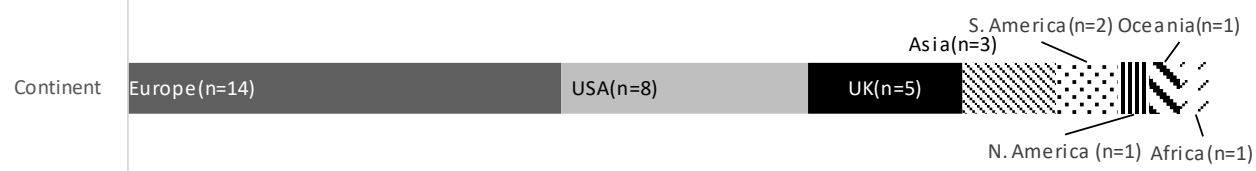

Participants

Farmers $(n=20)$

$\operatorname{Vets}(n=8)$

Multi-stakeholder(n=7)

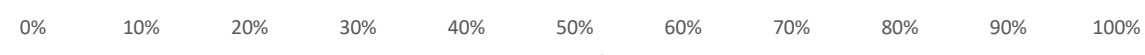

Percentage of studies

847

848

849

850

851

852

853

854

855

856

857

858

859

860

861

862

863

864 Farrell, Figure 3

865 


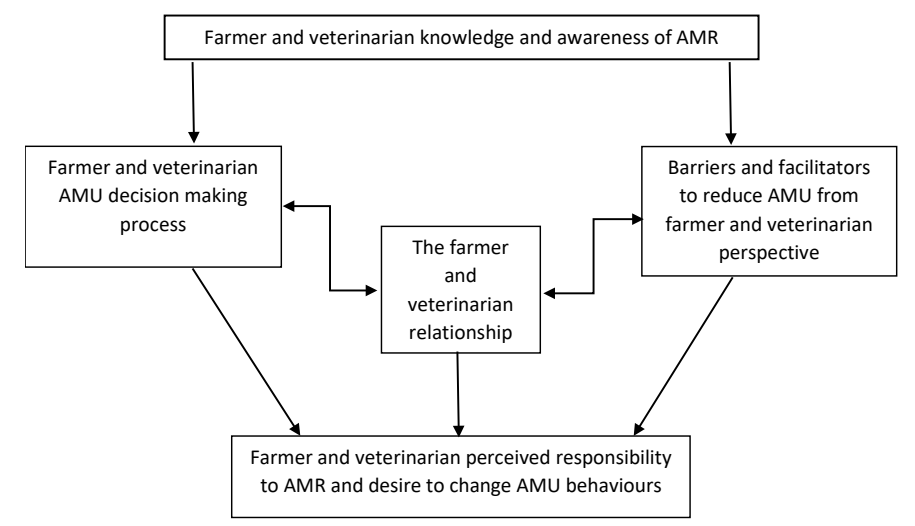

867

868

869

870

871

872

873

874

875

876 
891

892

893

894

895

896

897

898

899

900

901

902

903

904

905

906

907

908

909

910

911

912

913

914

915

916

917

918

919

920

Figure 1: PRISMA flow diagram of literature review process for studies on dairy farmer and veterinarians' current practices, attitudes \& perceptions of AMR and reducing AMU.

Figure 2: Summary of review study characteristics ( $n=$ number of studies)

Figure 3: Overview of key themes identified through thematic analysis

(1)

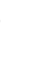

0

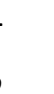

03

4




\section{DAIRY ANTIMICROBIAL USE: A SYSTEMATIC REVIEW}

921 Arnold, C., G. Schüpbach-Regula, P. Hirsiger, J. Malik, P. Scheer, X. Sidler, P. Spring, J. Peter-Egli,

922 and M. Harisberger. 2016. Risk factors for oral antimicrobial consumption in Swiss fattening pig

923 farms - a case control study. Porcine Health Manag. 2:5. https://doi.org/10.1186/s40813-016-0024-3

924 Bock, B.B. M.M. Van Huik, M. Prutzer, F. Kling Eveillard, and A. Dockes. 2007. Farmers

925 relationship with different animals: the importance of getting close to the animals. Int J Sociol

926 Agriculture. 15:3. ISSN: 0798-1759.

927 Braun, V., and V. Clarke. 2006. Using thematic analysis in psychology. Qual Res Psychol. 3:77-101.

928 10.1191/1478088706qp063oa

929

Broom, A., J. Broom, and E. Kirby. 2014. Cultures of resistance? A Bourdieusian analysis of doctors' antibiotic prescribing. Soc sci med. 110:81-88. https://doi.org/10.1016/j.socscimed.2014.03.030 knowledge, attitudes and practice of Italian beef and dairy cattle veterinarians concerning the use of antibiotics. Vet. Rec. 155:733-738.

Carmo, L.P., L.R. Nielsen, L. Alban, P.M. da Costa, G. Schüpbach-Regula, and I. Magouras. 2018.

Veterinary expert opinion on potential drivers and opportunities for changing antimicrobial usage practices in livestock in Denmark, Portugal, and Switzerland. Front Vet Sci. 5. https://doi.org/10.3389/fvets.2018.00029

Carmo, L., G. Schüpbach-Regula, C. Müntener, A, Chevance, G. Moulin, and I. Magouras. 2017. Approaches for quantifying antimicrobial consumption per animal species based on national sales data: a Swiss example, 2006-2013. Euro Surveill. 22. 10.2807/1560-7917.ES.2017.22.6.30458

941 Cattaneo, A.A., R. Wilson, D. Doohan, and J.T. LeJeune. 2009. Bovine veterinarians' knowledge, beliefs, and practices regarding antibiotic resistance on Ohio dairy farms. J. Dairy Sci. 92:3494-3502. $10.3168 /$ jds. $2008-1575$ 


\section{DAIRY ANTIMICROBIAL USE: A SYSTEMATIC REVIEW}

946 Chauhan, A.S., M.S. George, P. Chatterjee, J. Lindahl, D. Grace, and M. Kakkar. 2018. The social

947 biography of antibiotic use in smallholder dairy farms in India. Antimicrob Resist Infect Control.

948 7:60. https://doi.org/10.1186/s13756-018-0354-9

949 Coenen, S., B. Michiels, P. Van Royen, J.C. Van der Auwera, and J. Denekens. 2002. Antibiotics for 950 coughing in general practice: A questionnaire study to quantify and condense the reasons for 951 prescribing. BMC Fam pract. 3:16. https://doi.org/10.1186/1471-2296-3-16

952 Coyne, L. A., S.M. Latham, N.J. Williams, S. Dawson, I.J. Donald, R.B. Pearson, R.F. Smith, and 953 G.L. Pinchbeck. 2016. Understanding the culture of antimicrobial prescribing in agriculture: a 954 qualitative study of UK pig veterinary surgeons. J. Antimicrob. Chemother. 71:3300-3312. https://doi.org/10.1093/jac/dkw300

Coyne, L. A., G.L. Pinchbeck, N.J. Williams, R.F. Smith, S. Dawson, R.B. Pearson, and S.M. Latham. 2014. Understanding antimicrobial use and prescribing behaviours by pig veterinary surgeons and farmers: a qualitative study. Vet. Rec. 176:593. https://doi.org/10.1136/vr.102686

959 Critical Appraisal Skills Programme (CASP). CASP qualitative research checklist. 2017

960 http://www.phru.nhs.uk/Doc_Links/Qualitative\%20Appraisal\%20Tool.pdf

961 De Briyne, N., J. Atkinson, S. Borriello, and L. Pokludova. 2014. Antibiotics used most commonly to 962 treat animals in Europe. Vet Rec. 175. doi:10.1136/vr.102462.

963 De Briyne, N., J. Atkinson, L. Pokludová, S.P. Borriello, and S. Price. 2013. Factors influencing 964 antibiotic prescribing habits and use of sensitivity testing amongst veterinarians in Europe. Vet. Rec. 173:475. https://doi.org/10.1136/vr.101454

966 Ekakoro, J.E., M. Caldwell, E.B. Strand, and C.C. Okafor 2018. Drivers of Antimicrobial Use 967 Practices among Tennessee Dairy Cattle Producers. Vet Med Int. 2018: 1836836. production. Sociol Q. 55:92-118. https://doi.org/10.1111/tsq.12047 


\section{DAIRY ANTIMICROBIAL USE: A SYSTEMATIC REVIEW}

970

971

972

973

974

975

976

977

978

979

980

981

982

983

984

985

986

987

988

989

990

991

992

993

Ellis-Iversen, J., A. J. Cook, E. Watson, M. Nielen, L. Larkin, M. Wooldridge, and H. Hogeveen. 2010. Perceptions, circumstances and motivators that influence implementation of zoonotic control programs on cattle farms. Prev. Vet. Med. 93:276-285. doi:10.1016/j.prevetmed.2009.11.005

Etienne, J., S. Chirico, T. Gunabalasingham, S. Dautzenberg, and S. Gysen. 2017. EU insights: perceptions of the human health impact of amr and antibiotics use in animals across the EU. EFSA Support pub. 14:1183E. https://doi.org/10.2903/sp.efsa.2017.EN-1183

FAO (Food and Agriculture Organization). 2016. The FAO Action Plan on Antimicrobial Resistance. Rome: Food and Agriculture Organization of the United Nations. Pages. 3-25. Available from: http://www.fao.org/3/a-i5996e.pdf

FAO/OIE/WHO (2017) The Tripartite's Commitment—Providing multi-sectoral, collaborative leadership in addressing health challenges. FAO/OIE/WHO.

https://www.who.int/zoonoses/tripartite_oct2017.pdf

Festinger, L. 1957. A theory of cognitive dissonance. Stanford university press. Palo Alto. CA.

Fischer, K., K. Sjöström, A. Stiernström, and U. Emanuelson. 2019. Dairy farmers' perspectives on antibiotic use: A qualitative study. J. Dairy Sci. 102:2724-2737. https://doi.org/10.3168/jds.201815015

Fishbein, M., and J.N. Cappella. 2006. The Role of Theory in Developing Effective Health Communications. J Commun. 56:S1-S17. https://doi.org/10.1111/j.1460-2466.2006.00280.x

Friedman, D.B., C.P. Kanwat, M.L. Headrick, N.J. Patterson, J.C. Neely, and L.U. Smith. 2007. Importance of Prudent Antibiotic Use on Dairy Farms in South Carolina: A Pilot Project on Farmers' Knowledge, Attitudes and Practices. Zoonoses Public Health. 54:366-375.

Fynbo L., and C.S. Jensen. 2018. Antimicrobial stigmatization: Public health concerns about conventional pig farming and pig farmers' experiences with stigmatization. Soc Sci Med. 201:1-8. doi:10.1016/j.socscimed.2018.01.036 


\section{DAIRY ANTIMICROBIAL USE: A SYSTEMATIC REVIEW}

994 Gaertner, S.L., J.F. Dovidio, P.A. Anastasio, B.A. Bachman, and M.C. Rust. 1993. The Common

995 Ingroup Identity Model: Recategorization and the Reduction of Intergroup Bias. Eur Rev Soc Psychol.

996 4:1-26. doi:10.1080/14792779343000004

997 Garforth, C.J., A.P. Bailey, and R.B. Tranter. 2013. Farmers' attitudes to disease risk management in

998 England: a comparative analysis of sheep and pig farmers. Prev. Vet. Med. 110:456-466. doi:

$999 \quad 10.1016 /$ j.prevetmed.2013.02.018

1000 Gibbons, J., F. Boland, J. Buckley, F. Butler, J. Egan, S. Fanning, B. Markey, and F. Leonard. 2013.

1001 Influences on antimicrobial prescribing behaviour of veterinary practitioners in cattle practice in

1002 Ireland. Vet. Rec. 172:14. doi:10.1136/vr.100782.

1003

Golding S.E., J. Ogden, and H.M. Higgins. 2019. Shared goals, different barriers: A qualitative study

1004

of UK veterinarians' and farmers' beliefs about antimicrobial resistance and stewardship. Front Vet

1005

Sci. 6:132. doi:10.3389/fvets.2019.00132

1006

Hickman, L.D., J.L. Phillips, P.J. Newton, E.J. Halcomb, N. Al Abed, and P.M. Davidson. 2015.

1007

Multidisciplinary team interventions to optimise health outcomes for older people in acute care

1008

settings: A systematic review. Arch Gerontol Geriatr. 61:322-329. doi:10.1016/j.archger.2015.06.021

1009

Higgins, H.M., S.E. Golding, J. Mouncey, I. Nanjiani, and A.J.VC. Cook. 2017. Understanding

1010

veterinarians' prescribing decisions on antibiotic dry cow therapy. J. Dairy Sci. Journal of Dairy

1011

Science. 100:2909-2916. https://doi.org/10.3168/jds.2016-11923

1012

Higgins, H.M., J.N. Huxley, W. Wapenaar, and M.J. Green. 2013. Proactive dairy cattle disease

1013

control in the UK: veterinary surgeons' involvement and associated characteristics. Vet. Rec. 173:246.

1014

https://doi.org/10.1136/vr.101692

1015

Higham, L.E., A. Deakin, E. Tivey, V. Porteus, S. Ridgway, and A.C. Rayner. 2018. A survey of

dairy cow farmers in the United Kingdom: knowledge, attitudes and practices surrounding

1017

antimicrobial use and resistance. Vet. Rec. 183:746. doi:10.1136/vr.104986 


\section{DAIRY ANTIMICROBIAL USE: A SYSTEMATIC REVIEW}

1018

1019

1020

1021

1022

1023

1024

1025

1026

1027

1028

1029

1030

1031

1032

1033

1034

1035

1036

1037

1038

1039

1040

Higham, L.E., W. Ongeri, K. Asena, and M.V. Thrusfield. 2016. Characterising and comparing drugdispensing practices at animal health outlets in the Rift Valley, Kenya: an exploratory analysis (part II). Trop Anim Health Prod. 48:1633-1643. doi: 10.1007/s11250-016-1137-z

Hockenhull, J., A.E. Turner, K.K. Reyher KK, D.C. Barrett, L. Jones, S. Hinchliffe, and H.J. Buller. 2017. Antimicrobial use in food-producing animals: a rapid evidence assessment of stakeholder practices and beliefs. Vet. Rec. The Veterinary Record. 181:510. doi:10.1136/vr.104304.

Hudson, J.A., L.J. Frewer, G. Jones, P.A. Brereton, M.J. Whittingham, and G. Stewart. 2017. The agri-food chain and antimicrobial resistance: A review. Trends Food Sci Technol. 69(A):131-147. https://doi.org/10.1016/j.tifs.2017.09.007

Islam, J., D. Ashiru-Oredope, E. Budd, P. Howard, A.S. Walker, S. Hopkins, and M.J. Llewelyn. 2018. A national quality incentive scheme to reduce antibiotic overuse in hospitals: evaluation of perceptions and impact. J. Antimicrob. Chemother. 73:1708-1713. https://doi.org/10.1093/jac/dky041

Jansen, J., C.D.M. Steuten, R.J. Renes, N. Aarts, and T.J.G.M. Lam. 2010. Debunking the myth of the hard to reach farmer: effective communication on udder health. J. Dairy Sci. 93: 1296-1306.

https://doi.org/10.3168/jds.2009-2794

Jetten, J., S.A. Haslam, T. Cruwys, K.H. Greenaway, C. Haslam, and N.K. Steffens. 2017. Advancing the social identity approach to health and well-being: Progressing the social cure research agenda. Eur J Soc Psychol. 47:789- 802. doi:10.1002/ejsp.2333.

Johnson, I., A. Hansen, and P. Bi. 2018. The challenges of implementing an integrated One Health surveillance system in Australia. Zoonoses Public Health. 65:e229-e236. doi:10.1111/zph.12433

Jones, P.J., E.A. Marier, R.B. Tranter, G. Wu, E. Watson, and C.J. Teale. 2015. Factors affecting dairy farmers' attitudes towards antimicrobial medicine usage in cattle in England and Wales. Prev. Vet. Med. 21:30-40. https://doi.org/10.1016/j.prevetmed.2015.05.010 


\section{DAIRY ANTIMICROBIAL USE: A SYSTEMATIC REVIEW}

1041 Kabera, F., Dufour, S., Keefe, G., Cameron, M. \& Roy, J., 2020. Evaluation of quarter-based selective 1042 dry cow therapy using Petrifilm on-farm milk culture: A randomized controlled trial. Journal of Dairy 1043 Science, 103(8), pp.7276-7287.

1044 Kayitsinga, J., R.L. Schewe, G.A. Contreras, and R.J. Erskine. 2017. Antimicrobial treatment of 1045 clinical mastitis in the eastern United States: The influence of dairy farmers' mastitis management and 1046 treatment behavior and attitudes. J. Dairy Sci. 100:1388-1407. https://doi.org/10.3168/jds.2016-11708

1047 Kramer, T., L. Jansen, L. Lipman, L. Smit, D. Heederik, and A. Dorado-García. 2017. Farmers' 1048 knowledge and expectations of antimicrobial use and resistance are strongly related to usage in Dutch 1049 livestock sectors. Prev. Vet. Med. 147:142-148. https://doi.org/10.1016/j.prevetmed.2017.08.023 Kreuter, M.W., V.J. Strecher, and B. Glassman. 1992. One size does not fit all: the case for tailoring print materials. Ann Behav Med. 21:276-283. doi:10.1007/BF02895958

Kumar, V. and J. Gupta. 2018. Awareness of dairy farmers about antibiotic resistance in Eastern Haryana region. Indian Journal of Dairy Science. 71:625-630.

1054 Laanen, M., D. Persoons, S. Ribbens, E. de Jong, B. Callens, M. Strubbe, D. Maes, and J. Dewulf, 1055 2013. Relationship between biosecurity and production/antimicrobial treatment characteristics in pig 1056 herds. Vet. J. 198:508-512. doi:10.1016/j.tvj1.2013.08.029 M.J. Newman. 2018. Physicians' knowledge, attitudes, and perceptions concerning antibiotic resistance: a survey in a Ghanaian tertiary care hospital. BMC Health Serv Res. 18:126. https://doi.org/10.1186/s12913-018-2899-y Mertens, M. Schumacher, and M. Wolkewitz. 2011. Clinical outcomes of health-care-associated infections and antimicrobial resistance in patients admitted to European intensive-care units: a cohort study. Lancet Infect Dis. 11:30-38. https://doi.org/10.1016/S1473-3099(10)70258-9 


\section{DAIRY ANTIMICROBIAL USE: A SYSTEMATIC REVIEW}

1065

1066

1067

1068

1069

1070

1071

1072

1073

1074

1075

1076

1077

1078

1079

1080

1081

1082

1083

1084

1085

1086

1087

1088

Landfried, L.K., E.K. Barnidge, P. Pithua, R.D. Lewis, J.A. Jacoby, C.C. King, and C.R. Baskin. 2018. Antibiotic Use on Goat Farms: An Investigation of Knowledge, Attitudes, and Behaviors of Missouri Goat Farmers. Animals (Basel). 8:198. https://doi.org/10.3390/ani8110198

Lathers, C.M. 2001. Role of veterinary medicine in public health: antibiotic use in food animals and humans and the effect on evolution of antibacterial resistance. J Clin Pharmacol. 41:595-599. https://doi.org/10.1177/00912700122010474

Léger, D.F., N.C. Newby, R. Reid-Smith, N. Anderson, D.L. Pearl, K.D. Lissemore, and D.F. Kelton. 2015. Antimicrobial dispensing by Ontario dairy veterinarians. Can. Vet. J. 56:723-729.

Lhermie, G., D. Wernli, P.S. Jørgensen, D. Kenkel, C.L. Lawell, L.W. Tauer, and Y.T. Gröhn. 2019. Tradeoffs between resistance to antimicrobials in public health and their use in agriculture: Moving towards sustainability assessment. Ecol Econ. 166:106427.

https://doi.org/10.1016/j.ecolecon.2019.106427

Magalhaes-Sant'Ana, M., S.J. More, D.B. Morton, and A.J. Hanlon. 2017. Challenges facing the veterinary profession in Ireland: 2. On-farm use of veterinary antimicrobials. Ir Vet J. 70:28.

https://doi.org/10.1186/s13620-017-0106-9

Manyi-Loh, C., Mamphweli, S., Meyer, E., \& Okoh, A. (2018). Antibiotic Use in Agriculture and Its Consequential Resistance in Environmental Sources: Potential Public Health Implications. Molecules (Basel, Switzerland), 23(4), 795. https://doi.org/10.3390/molecules23040795

Mateus, A.L., D.C. Brodbelt, N. Barber, and K.D. Stärk. 2014. Qualitative study of factors associated with antimicrobial usage in seven small animal veterinary practices in the UK. Prev. Vet. Med. 117:68-78. doi:10.1016/j.prevetmed.2014.05.007

McDougall, S., C.W.R. Compton, and N. Botha. 2017. Factors influencing antimicrobial prescribing by veterinarians and usage by dairy farmers in New Zealand. N Z Vet J. 65:84-92. https://doi.org/10.1080/00480169.2016.1246214 


\section{DAIRY ANTIMICROBIAL USE: A SYSTEMATIC REVIEW}

1089

1090

1091

1092

1093

1094

1095

1096

1097

1098

1099

1100

1101

1102

1103

1104

1105

1106

1107

1108

1109

1110

1111

1112

McIntosh, W., and W. Dean. 2015. Factors Associated with the Inappropriate Use of Antimicrobials. Zoonoses Public Health. 62:22-28. doi:10.1111/zph.12169

Moher, D., A. Liberati, J. Tetzlaff, D.G. Altman. 2009. The PRISMA Group (2009) Preferred Reporting Items for Systematic Reviews and Meta-Analyses: The PRISMA Statement. PLoS Med 6(7): e1000097. https://doi.org/10.1371/journal.pmed.1000097

Moreno, M.A. 2014. Opinions of Spanish pig producers on the role, the level and the risk to public health of antimicrobial use in pigs. Res. Vet. Sci. 97:26-31. doi: 10.1016/j.rvsc.2014.04.006

Morris, C., R. Helliwell, and S. Raman. 2016. Framing the agricultural use of antibiotics and antimicrobial resistance in UK national newspapers and the farming press. J Rural Stud. 45:43-53. doi:10.1016/j.jrurstud.2016.03.003.

Mudge, A.M., S. Laracy, K. Richter, and C. Denaro. 2006. Controlled trial of multidisciplinary care teams for acutely ill medical inpatients: Enhanced multidisciplinary care. Intern Med J. 36:558-63. doi:10.1111/j.1445-5994.2006.01135.x.

Nicholson, A., I. Tennant, L. White, C.A. Thoms-Rodriguez, L. Cook, S. Johnson, T. Thompson, J. Barnett, and L. Richards. 2018. The knowledge, attitudes and practices of doctors regarding antibiotic resistance at a tertiary care institution in the Caribbean. Antimicrob Resist Infect Control. 7:23. https://doi.org/10.1186/s13756-018-0315-3

O'Neill, J. 2014. Antimicrobial Resistance: Tackling a crisis for the health and wealth of nations. UK: UK Government.

Orpin, P. 2017. What can we learn from farmers experiences and attitudes to Selective Dry Cow Therapy? Cattle Pract. 25:130-139.

Ozturk, Y., S. Celik, E. Sahin, M.N. Acik, and B. Cetinkaya. 2019. Assessment of Farmers' Knowledge, Attitudes and Practices on Antibiotics and Antimicrobial Resistance. Animals (Basel). 9:653. https://doi.org/10.3390/ani9090653 


\section{DAIRY ANTIMICROBIAL USE: A SYSTEMATIC REVIEW}

Paredes, P., M. de la Peña, E. Flores-Guerra, J. Diaz, and J. Trostle. 1996 Factors influencing physicians' prescribing behaviour in the treatment of childhood diarrhoea: knowledge may not be the clue. Soc Sci Med. 42:1141-1153. doi:10.1016/0277-9536(95)00387-8

Poizat A., F. Bonnet-Beaugrand, A. Rault, C. Fourichon, and N. Bareille. 2017. Antibiotic use by farmers to control mastitis as influenced by health advice and dairy farming systems. Prev. Vet. Med. 146:61-72. doi: 10.1016/j.prevetmed.2017.07.016

Postma, M., A. Backhans, L. Collineau, S. Loesken, M. Sjölund, C. Belloc, U. Emanuelson, E. Grosse Beilage, K.D.C. Starl., and J. Dewulf. 2016. The biosecurity status and its associations with production and management characteristics in farrow-to-finish pig herds. Animal. 10:478-489. doi:10.1017/S1751731115002487

Postma, M., K.D. Stärk, M. Sjölund, A. Backhans, E.G. Beilage, S. Lösken, C. Belloc, L. Collineau, D. Iten, V. Visschers, E.O. Nielsen, J. Dewulf, and MINAPIG consortium. 2015. Alternatives to the use of antimicrobial agents in pig production: A multi-country expert-ranking of perceived effectiveness, feasibility and return on investment. Prev. Vet. Med. 118:457-466. https://doi.org/10.1016/j.prevetmed.2015.01.010

Prestinaci, F., P. Pezzotti, and A. Pantosti. 2015. Antimicrobial resistance: a global multifaceted phenomenon. Pathog Glob Health. 109:309-318. doi:10.1179/2047773215Y.0000000030

Raymond, M.J., R.D. Wohrle, and D.R. Call. 2006. Assessment and promotion of judicious antibiotic use on dairy farms in Washington state. J. Dairy Sci. 89:3228-3240. https://doi.org/10.3168/jds.S0022-0302(06)72598-X

Redding, L.E., F.K. Barg, G. Smith, D.T. Galligan, M.Z. Levy, and S. Hennessy. 2013. The role of veterinarians and feed-store vendors in the prescription and use of antibiotics on small dairy farms in rural Peru. J. Dairy Sci. 96:7349-7354. http://dx.doi.org/ 10.3168/jds.2013-7045 


\section{DAIRY ANTIMICROBIAL USE: A SYSTEMATIC REVIEW}

Redding, L.E., F. Cubas-Delgado, M.D. Sammel, G. Smith, D.T. Galligan, M.Z. Levy, and S. Hennessy. 2014. The use of antibiotics on small dairy farms in rural Peru. Prev. Vet. Med. 113:88-95. doi:10.1016/j.prevetmed.2013.10.012

Reyher, K.K., D.C. Barrett, and D.A. Tisdall. 2017. Achieving responsible antimicrobial use: Communicating with farmers. In Pract. 39:63-71. doi:10.1136/inp.j341

Ritter, C., J. Jansen, S. Roche, D.F. Kelton, C.L. Adams, K. Orsel, R.J. Erskine, G. Benedictus, T.J.G.M. Lam, and H.W. Barkema. 2017. Invited review: determinants of farmers' adoption of management-based strategies for infectious disease prevention and control. J. Dairy Sci. 100:3329_ 3347. doi:10.3168/jds.2016-11977

Rojo-Gimeno, C., M. Postma, J. Dewulf, H. Hogeveen, L. Lauwers, and E. Wauters E. 2016. Farmeconomic analysis of reducing antimicrobial use whilst adopting improved management strategies on farrow-to-finish pig farms. Prev. Vet. Med. 129:74-87. doi: 10.1016/j.prevetmed.2016.05.001

Ruegg, P.L. 2006. Basic epidemiologic concepts related to assessment of animal health and performance. Vet. Clin. North Am. Food Anim. Pract. 22:1-19 DOI: 10.1016/j.cvfa.2005.12.002

Ruegg PL. 2017. A 100-Year Review: Mastitis detection, management, and prevention. J. Dairy Sci. 100:10381-10397. doi:10.3168/jds.2017-13023

Rüegg, S.R., B.J. McMahon, B. Häsler, R. Esposito, L.R. Nielsen, C. Ifejika Speranza, T. Ehlinger, M. Peyre, M. Aragrande, J. Zinsstag, P. Davies, A.D. Mihalca, S.C. Buttigieg, J. Rushton, L.P. Carmo, D. De Meneghi, M. Canali, M.E. Filippitzi, F.L. Goutard, V. Ilieski, and A. Lindberg. 2017. A Blueprint to Evaluate One Health. Front Public Health. 5:20. https://doi.org/10.3389/fpubh.2017.00020

Sadiq, M.B., S.S. Syed-Hussain, S.Z. Ramanoon, A.A. Saharee, N.I. Ahmad, M.Z. Noraziah, S.F. Khalid, D.S. Naseeha, A.A. Syahirah, and R. Mansor. 2018. Knowledge, attitude and perception regarding antimicrobial resistance and usage among ruminant farmers in Selangor, Malaysia. Prev. Vet. Med. 156:76-83. doi:10.1016/j.prevetmed.2018.04.013 


\section{DAIRY ANTIMICROBIAL USE: A SYSTEMATIC REVIEW}

1161

1162

1163

1164

1165

1166

1167

1168

1169

1170

1171

1172

1173

1174

1175

1176

1177

1178

1179

1180

1181

1182

1183

1184

Salisbury, J., T. Nicholls, A. Lammerding, J. Turnidge, and M. Nunn. 2002. A risk analysis

framework for the long-term management of antibiotic resistance in food animals. Int. J. Antimicrob.

Agents. 20:153-64. 10.1016/S0924-8579(02)00169-3.

Sawant, A., L. Sordillo, and B. Jayarao. 2005. A survey on antibiotic usage in dairy herds in

Pennsylvania. J. Dairy Sci. 88:2991-2999. https://doi.org/10.3168/jds.S0022-0302(05)72979-9

Scherpenzeel, C.G.M., I.M.G.A. Santman-Berends, and T.J.G.M. Lam. 2018. Veterinarians' attitudes toward antimicrobial use and selective dry cow treatment in the Netherlands. J. Dairy Sci. 101:63366345. https://doi.org/10.3168/jds.2017-13591

Scherpenzeel, C.G.M., S.H.W. Tijs, I.E.M. den Uijl, I.M.G.A. Santman-Berends, A.G.J. Velthuis, and T.J.G.M. Lam. 2016. Farmers attitude toward the introduction of selective dry cow therapy. J. Dairy Sci.99:8259-8266. doi:10.3168/jds.2016-11349

Sheehan R. Summary of UK Veterinary Prescribing Pressures Focus Groups. (2013). Available online at: https://webarchive.nationalarchives.

gov.uk/20140909112048/https://www.vmd.defra.gov.uk/pdf/Summary_FocusGroups.pdf (accessed February 9, 2019).

Shortall, O., L.A. Sutherland, A. Ruston, and J. Kaler. 2018. True Cowmen and Commercial Farmers: Exploring Vets' and Dairy Farmers' Contrasting Views of 'Good Farming' in Relation to Biosecurity. Sociologia Ruralis. DOI:10.1111/soru.12205

Smith, M., C. King, M. Davis, A. Dickson, J. Park, F. Smith, K. Currie, and P. Flowers. 2018. Pet owner and vet interactions: exploring the drivers of AMR. Antimicrob Resist Infect Control. 7:46. https://doi.org/10.1186/s13756-018-0341-1

Speksnijder D.C., A.D.C. Jaarsma, A.C. van der Gugten, T.J.M. Verheij, and J.A. Wagenaar. 2015. Determinants associated with veterinary antimicrobial prescribing in farm animals in the Netherlands: A qualitative study. Zoonoses Public Health. 62:39-51. doi: 10.1111/zph.12168 


\section{DAIRY ANTIMICROBIAL USE: A SYSTEMATIC REVIEW}

Speksnijder, D.C., and J.A. Wagenaar. 2018. Reducing antimicrobial use in farm animals: how to support behavioral change of veterinarians and farmers. Anim Front. 8:4-9.

https://doi.org/10.1093/af/vfy006

Swinkels, J.M., A. Hilkens, V. Zoche-Golob, V. Kroemker, M. Buddiger, J. Jansen, and T.J.G.M. Lam. 2015. Social influences on the duration of antibiotic treatment of clinical mastitis in dairy cows. J. Dairy Sci. 98:2369-2380. doi:10.3168/jds.2014-8488

Tang, K.L., N.P. Caffrey, D.B. Nóbrega, S.C. Cork, P.E. Ronksley, H.W. Barkema, A.J. Polachek, H. Ganshorn, N. Sharma, J.D. Kellner, and W.A. Ghali. 2017. Restricting the use of antibiotics in foodproducing animals and its associations with antibiotic resistance in food-producing animals and human beings: a systematic review and meta-analysis. Lancet Planet Health. 1:e316-e327. https://doi.org/10.1016/S2542-5196(17)30141-9

Teillant, A., S. Gandra, D. Barter, D.J. Morgan, and R. Laxminarayan. 2015. Potential burden of antibiotic resistance on surgery and cancer chemotherapy antibiotic prophylaxis in the USA: a literature review and modelling study. Lancet Infect Dis. 15:1429-37. https://doi.org/10.1016/S1473$3099(15) 00270-4$

Teixeira Rodrigues, A., F. Roque, A. Falcão, A. Figueiras, and M.T. Herdeiro. 2013. Understanding physician antibiotic prescribing behaviour: a systematic review of qualitative studies. Int. J. Antimicrob. Agents. 41:203-212. doi:10.1016/j.ijantimicag.2012.09.003

Tong, A., K. Flemming, E. McInnes, S. Oliver, and J. Craig. 2012. Enhancing transparency in reporting the synthesis of qualitative research: ENTREQ. BMC Medical Research Methodology, 12(1).

Tong, A., P. Sainsbury, and J. Craig. 2007. Consolidated criteria for reporting qualitative research (COREQ): a 32-item checklist for interviews and focus groups. Int J Qual Health Care. 19:349-57. 


\section{DAIRY ANTIMICROBIAL USE: A SYSTEMATIC REVIEW}

Tonkin-Crine, S., L. Yardley, and P. Little. 2011. Antibiotic prescribing for acute respiratory tract infections in primary care: a systematic review and meta-ethnography. J. Antimicrob. Chemother. 66:2215-2223. https://doi.org/10.1093/jac/dkr279

Turner, A., D. Tisdall, D. Barrett, S. Wood, A. Dowsey, and K. Reyher. 2018. Ceasing the use of the highest priority critically important antimicrobials does not adversely affect production, health or welfare parameters in dairy cows. Vet. Rec. 183:67. 10.1136/vr.104702.

Turner, J.C., P.J. Oakes, A. Haslam, and C. McGarty. 1994. Self and collective: Cognition and social context. Pers Soc Psychol Bull. 2:454-463. doi:10.1177/0146167294205002

Vaarst, M., B. Paarup-Laursen, H. Houe, C. Fossing, and H.J. Andersen. 2002. Farmers' choice of medical treatment of mastitis in Danish dairy herds based on qualitative research interviews. J. Dairy Sci. 85:992-1001. doi: 10.3168/jds.s0022-0302(02)74159-3

Vaarst, M., S. Thamsborg, T. Bennedsgaard, H. Houe, C. Enevoldsen, F. Aarestrup, and A. de Snoo. 2003. Organic dairy farmers' decision making in the first 2 years after conversion in relation to mastitis treatments. Livest. Prod. Sci. 80:109-120. https://doi.org/10.1016/S0301-6226(02)00310-X

Van den Borne, B.H.P., F.J.S. van Soest, M. Reist, and H. Hogeveen. 2017. Quantifying preferences of farmers and veterinarians for national animal health programs: the example of bovine mastitis and antimicrobial usage in Switzerland. Front Vet Sci. 4:1-13. doi:10.3389/fvets.2017.00082

van Dijk, L., A. Hayton, D.C.J. Main, A. Booth, A. King, D.C. Barrett, H.J. Buller, and K.K. Reyher. 2017. Participatory Policy Making by Dairy Producers to Reduce Anti-Microbial use on Farms. Zoonoses Public Health. 64:476-484. doi:10.1111/zph.12329

Vasquez A.K., C. Foditsch, S.A.C. Duliepre, J.D. Siler, D.R. Just, L.D. Warnick, D.V. Nydam, and J. Sok. 2019. Understanding the effect of producers' attitudes, perceived norms, and perceived behavioral control on intentions to use antimicrobials prudently on New York dairy farms. PLoS ONE e0222442. doi:10.1371/journal.pone.0222442 


\section{DAIRY ANTIMICROBIAL USE: A SYSTEMATIC REVIEW}

1232 Visschers, V.H.M., A. Backhans, L. Collineau, D. Iten, S. Loesken, M. Postma, C. Belloc, J. Dewulf,

1233 U. Emanuelson, E.G. Beilage, M. Siegrist, M. Sjölund, and K.D. Stärk. 2015. Perceptions of

1234 antimicrobial usage, antimicrobial resistance and policy measures to reduce antimicrobial usage in convenient samples of Belgian, French, German, Swedish and Swiss pig farmers. Prev. Vet. Med. 119:10-20. doi:10.1016/j.prevetmed.2015.01.018

1237

Visschers, V.H.M., A. Backhans, L. Collineau, S. Loesken, E.O. Nielsen, M. Postma, C. Belloc, J.

Dewulf, U. Emanuelson, E. Grosse Beilage, M. Siegrist, M. Sjolund, and K.D.C. Stark. 2016. A comparison of pig farmers' and veterinarians' perceptions and intentions to reduce antimicrobial usage in six European countries. Zoonoses Public Health. 63:1-11. https://doi.org/10.1111/zph.12260

WHO (World Health Organization). 2000. WHO Global principles for the containment of antimicrobial resistance in animals intended for food: report of a WHO consultation with the

1243 participation of the Food and Agriculture Organization of the United Nations and the Office

1244 International des Epizooties. World Health Organization, Geneva, Switzerland.

WHO (World Health Organization). 2014. Antimicrobial resistance: global report on surveillance.

World Health Organization, Geneva, Switzerland.

WHO (World Health Organization) 2015. Antibiotic Resistance: Multi-Country Public Awareness

Survey; World Health Organization: Geneva, Switzerland.

http://apps.who.int/medicinedocs/documents/s22245en/s22245en.pdf

WHO (World Health Organization). 2017. Fact Sheet: Antimicrobial Resistance 1-5. World Health Organization, Geneva, Switzerland.

Wilkie, R.M. 2005. Sentient commodities and productive paradoxes: the ambiguous nature of humanlivestock relations in Northeast Scotland. J Rural Stud. 21:213-230.

1254 https://doi.org/10.1016/J.JRURSTUD.2004.10.002 


\section{DAIRY ANTIMICROBIAL USE: A SYSTEMATIC REVIEW}

1255 Zwald, A.G., P.L. Ruegg, J.B. Kaneene, J.D. Warnick, S.J. Wells, C. Fossler, and L.W. Halbert. 2004. 1256 Management Practices and Reported Antimicrobial Usage on Conventional and Organic Dairy Farms. 1257 J Dairy Sci. 2004. 87:191-201. doi:10.3168/jds.S0022-0302(04)73158-6 